\title{
El uso del marketing digital para crear una empresa virtual para servicios de gestión de proyectos en Sudamérica
}

Trabajo Científico libre para la obtención del grado de Magister en Marketing Internacional de la Escuela de Postgrado de Marketing Internacional -Facultad de Ciencias Económicas

- Universidad Nacional de La Plata -

Profesor Director de la tesis:

Lic. Sebastián Torre
Presentado por:

Ing. Angelo José Albino Braga

Calle Maria Heilbuth Surette 70/101

Buritis - Belo Horizonte

Minas Gerais - Brasil

Fecha de entrega: 06-10-2014 
Índice Temático

1 Introducción 4

1.1 Descripción introductoria 4

$\begin{array}{ll}1.2 & \text { Preguntas problema } \\ 1.3 & \text { Objetivo General }\end{array}$

$\begin{array}{ll}1.3 \text { Objetivo General } & 7\end{array}$

$\begin{array}{lll}1.4 & \text { Objetivos específicos de investigación } & 7\end{array}$

1.5 Metodología 8

1.6 Justificación para la elección del tema 8

2 Herramientas de Marketing Digital 9

3 Elementos estratégicos para hacer negocios a través de Internet 12

$\begin{array}{ll}3.1 & 13 \\ 3.2 & \text { Investigación }\end{array}$

3.2 Planificación 16

$\begin{array}{ll}\text { 3.2.1 Segmentación del mercado } & 18\end{array}$

3.2.2 Beneficio que daremos para cada segmento 18

3.2.3 Factores críticos de éxito del negocio 18

$\begin{array}{ll}\text { 3.2.4 Posicionamientos adecuados para estos segmentos } & 18\end{array}$ escogidos

3.2.5 Equipo que trabajará en el departamento de Internet 19

3.2.6 Misiones críticas del sitio web 19

$\begin{array}{lll}3.2 .7 & \text { Alcance del site } & 19\end{array}$

3.2.8 Wireframe del sitio web 20

3.2.9 Layout y contenido del sitio web 20

3.2.10 Contenido para los medios de comunicación sociales 20

3.2.11 Contenido que será generado por el consumidor 21

3.2.12 Promociones propagadoras que lanzarán su empresa en 21 Internet

3.2.13 Campañas de e-mail marketing 21

3.3 Producción 21

3.3.1 Desarrollo del contenido direccionado para el consumidor 25

3.4 Publicación 26

3.4.1 Contenido direccionado para una buena clasificación en 26 Google

$\begin{array}{ll}3.4 .2 & \text { Links patrocinados }\end{array}$

$\begin{array}{lll}3.4 .3 & \text { Buscadores } & 27\end{array}$

3.4.4 Optimizando nuestro sitio web teniendo como base el 27 contenido

3.4.5 Criterios de optimización 28

3.4.6 Contenido de colaboración 30

3.4.7 Elementos persuasivos 30

$\begin{array}{ll}3.4 .8 \text { Contenido off-site } & 30\end{array}$

$\begin{array}{ll}3.4 .9 \text { Blogs } & 31\end{array}$

$\begin{array}{lll}3.5 & \text { Promoción } & 31\end{array}$

3.5.1 Campañas en medios de comunicación social 32

$\begin{array}{ll}3.5 .2 & \text { E-mail marketing }\end{array}$

3.6 Propagación 33

$\begin{array}{lll}3.6 .1 & \text { Facebook } & 34\end{array}$

$\begin{array}{lll}3.6 .2 & \text { Twitter } & 34\end{array}$

$\begin{array}{lll}3.6 .3 & \text { Linkedln } & 35\end{array}$

$\begin{array}{lll}3.6 .4 & \text { Redes sociales de nicho } & 37\end{array}$

$\begin{array}{lll}3.6 .5 & \text { Youtube } & 37\end{array}$ 
3.6.6 Interacción basada en la cooperación 37

3.7 Personalización 38

3.7.1 Personalización por medio de e-mail marketing 38

$\begin{array}{lll}3.8 & \text { Precisión } & 39\end{array}$

3.8.1 Monitoreo de nuestra palabra-clave 39

3.8.2 Página de entrada 40

3.8.3 Link externos 40

3.8.4 Como hacer las mediciones 40

3.8.5 Mensuración en redes sociales 40

3.8.6 Mensuración en e-mail marketing 41

$\begin{array}{lll}3.9 & \text { Consideraciones importante para nuestro proyecto } & 42\end{array}$

4 Proyecto para la creación de una empresa que usará solamente marketing 43

digital para su divulgación

4.1 Primera herramienta: sitio web de la empresa 47

4.2 Segunda herramienta: e-mail marketing 49

4.2.1 Elección del proveedor de servicios de e-mail (ESP) 50

4.2.2 Creación de nuestra lista 50

4.2.3 Planificación de la campaña 52

4.3 Tercera herramienta: blog 52

4.4 Cuarta herramienta: Podcast, Videocast y Fotos 53

4.5 Quinta herramienta: redes sociales 55

5 Estrategia para el crecimiento en América del Sur 56

6 Análisis de viabilidad de la creación de la empresa 58

6.1 Precios 58

6.2 Cobranza de los honorarios 60

6.3 Táctica para establecer los honorarios 61

6.4 Estrategias para la retención y relaciones 61

7 Conclusiones $\quad 62$

8 Anexos 63

9 Bibliografía 66 


\section{Introducción}

\subsection{Descripción Introductoria}

Con el advenimiento del Internet, surgió también una nueva forma de hacer negocios. Se trata del e-business, que es un término que describe el uso de medios electrónicos basados en Internet para dirigir la empresa. Adicionalmente, a través del e-commerce se puede comprar o vender productos o servicios y muchas de estas transacciones pueden realizarse online, es decir, en tiempo real ${ }^{1}$.

Con el término e-busines llegó también el término e-marketing que representa el esfuerzo de una empresa para promocionar y vender sus productos y servicios a través del Internet ${ }^{1}$. Basado en los conceptos anteriores, nacieron dos tipos de empresas: ${ }^{1}$

- Las empresas que nacieron en Internet (100\% virtuales)

- $\quad$ Y las empresas reales que añadieron un sitio web a su forma de hacer negocios Teniendo como base mi experiencia y en la observación de las actividades de nuestra vida cotidiana, podemos decir que las empresas de hoy en día están cada vez más globalizadas y algunas ya están buscando la creación de equipos virtuales para la realización de nuevos proyectos y del trabajo cotidiano. Estos equipos se forman para ejecutar proyectos que en su mayoría envuelven áreas geográficamente diferentes, y que necesitan de los equipos trabajando colaborativamente. Esto es muy común en proyectos de tecnología de la información (TI).

Hoy en día, hay una gran cantidad de empresas .com (punto com) totalmente virtuales, como buscadores, proveedores de servicios, sitios web comerciales que pueden llevar adelante los más diferentes tipos de negocios. Como ejemplo podemos citar los sitios web comerciales Amazon, eBay y Expedia. ${ }^{1}$

Observamos que en Brasil y en América del Sur, casi todas las grandes empresas poseen un sitio web. Eso se vuelve más evidente aún cuando verificamos empresas que actúan en el mercado de venta al por menor o con venta de servicios. Esto significa que los habitantes y las empresas de América del Sur ya están acostumbrados al uso de Internet así como los servicios originados por el Internet. Obviamente, esto fue sucediendo en un corto período de tiempo y dio origen a esta nueva forma de hacer negocios.

\footnotetext{
${ }^{1}$ Kotler, Philip Y Kevin Lane Keller. (2006)Administração de Marketing, São Paulo: Pearson Prentice Hall, Pag. 489
} 
Internet demostró ser útil para la realización de negocios ya que ofrece mayor comodidad en la compra de bienes o servicios, y, en algunos casos, es posible hasta conseguir un precio inferior (ejemplo de los e-books).

Entre tanto, cuando se compran productos que necesitan de pruebas antes de efectuar la compra, Internet no se muestra efectivo para estos casos. Para servicios que no son visibles (intangibles), puede ser una excelente herramienta para la compra y venta de los mismos. ${ }^{1}$ Sabemos que las empresas de hoy en día usan sus sitios web en Internet para realizar nuevos negocios. Por otro lado, no basta con publicar un sitio web para tener éxito inmediato, sino que debemos establecer una estrategia de marketing digital para que nuestra marca sea conocida en Internet. En cambio la combinación de una estrategia de marketing con un buen sitio web de buen contenido y facilidad de uso, hacen que nuestro negocio virtual sí sea un éxito.

Basado en lo expuesto, nuestro objetivo es crear una empresa virtual que ofrezca a sus clientes servicios en gestión de proyectos y cuya área de actuación sea toda América del Sur. Como los servicios ofrecidos serán de capacitación y consultoría, el cobro de los mismos no se realizará mediante medios de pago online sino a través de contratos que serán firmados entre las partes. Es decir, toda la promoción de la empresa y sus servicios se realizará a través de medios digitales y el cobro a través de contratos de prestación de servicios profesionales entre las partes cuyo pago efectivo será mediante la emisión de nota fiscal electrónica.

Para esto, los servicios usaran Internet como medio de ejecución y prestación de los mismos excepto cuando necesitemos de encuentros presenciales, especialmente en capacitación y en la consultoría. En este caso no serán usados medios digitales y sí contacto directo con el cliente, sea por teléfono o en encuentros presenciales.

Sabemos que Internet es un poderoso medio de comunicación, pero necesitamos entender cómo podemos utilizar eso en nuestro beneficio. Así estudiaremos las formas de actuación que podremos usar para que Internet sea el medio principal de promoción y venta de servicios de la empresa que inicialmente actuará en toda América del Sur.

Para obtener éxito en la creación de un negocio, necesitamos de un sistema inteligente, así como también de procedimientos y fuentes de información. Con la información obtenida, tomamos las decisiones sobre qué camino seguir. ${ }^{2}$

\footnotetext{
${ }^{1}$ Kotler, Philip Y Kevin Lane Keller. (2006) Administração de Marketing. São Paulo: Pearson Prentice Hall, Pag. 489
}

${ }^{2}$ Kotler, Philip Y Kevin Lane Keller. (2006)Administração de Marketing. São Paulo: Pearson Prentice Hall,, Pag. 73 
De esta manera entramos en una zona donde debemos conocer con profundidad como integrar la economía y la cyber-sociedad, porque la idea es derribar las barreras geográficas y promover la comunicación mediante un espacio virtual donde las empresas y los individuos pueden relacionarse con nuestra empresa. Para comunicarse y hacer la promoción de nuestros servicios, debemos buscar herramientas de marketing digital que nos auxiliarán en esa misión. Nuestra idea es comprender como estas herramientas nos ayudarán en el contexto.

Necesitamos construir nuestra marca en Internet para tener varios tipos de interacción con nuestros clientes y pensar que esa experiencia con la marca ayudará a construir una imagen positiva o negativa del negocio. Eso es fundamental para el éxito y manutención de la empresa. Este contacto con nuestros clientes hoy en día se puede hacer por medio de sitios web, Facebook, Twitter, blog, correo electrónico, buscadores y muchas otras formas de comunicación digital.

Usando estos medios, el consumidor estará siempre en contacto con nuestra empresa. En otras palabras, llegará a nuestra empresa mediante un clic. Entre tanto, para que esto acontezca, primero nuestro cliente nos debe de encontrar en el Internet. ${ }^{3}$

La virtualización de la empresa genera un problema, ya que se encuentra a medio camino entre muchas opciones y competidores y también porque está en un ambiente impersonal, el entorno virtual. Por otro lado, se rompen las barreras físicas de las distancias que evitarían nuestro ingreso en el mercado. Este es un punto positivo que ayuda a aprovechar el negocio porque nuestros clientes no están solamente en una única región geográfica.

Para facilitar el trabajo de divulgación de la empresa y de nuestra marca en Internet, los consumidores saben por experiencia que Internet hoy en día es una gran fuente de información y que existen diversos motores de búsqueda utilizados para encontrarla. Para eso debemos utilizar selectas palabras claves que faciliten a los consumidores encontrar nuestra marca. ${ }^{4}$

Para facilitar el ser encontrado, buscaremos evaluar las formas de comunicación a través de herramientas específicas o redes sociales para estar conectados online con este consumidor y así mejorar la presencia de nuestra empresa.

\footnotetext{
${ }^{3}$ Vaz, Conrad Adolpho. (2011) Os 8 Ps do marketing digital: o seu guia estratégico de marketing digital, São Paulo: Novatec, pag. 79 y 80

${ }^{4}$ Torres, Claudio. (2009) A Bíblia do Marketing Digital. São Paulo: Novatec Editora, pag. 30
} 
Para alcanzar estos objetivos analizaremos como la comercialización de contenidos de consumo debe ser trabajada y como debemos construir las herramientas de búsqueda para un mejor y mayor alcance a estos consumidores.

\subsection{Preguntas Problema}

* ¿Cuáles son las herramientas de marketing digitales más eficaces para alcanzar nuestro público objetivo?

* ¿Cómo demostrar los conocimientos y competencias para ganar clientes virtuales? ¿Cómo el marketing digital puede ayudarnos en este contexto?

* ¿Cómo atraer el deseo de los clientes usando marketing digital?

\subsection{Objetivo general}

Crear una empresa que usará herramientas digitales para el marketing y la promoción de los servicios de consultoría y capacitación en gestión de proyectos, cuya cobertura será toda América del Sur. Sin embargo el cobro de los servicios prestados no será hecho de forma virtual por el tipo de servicios, que son de consultoría y capacitación, servicios que demandan una charla detallada y la firma de contrato con el cliente. Inicialmente el enfoque de la empresa se dará en el mercado Brasileño que es el local matriz de la empresa. Sin embargo para abarcar América del Sur, buscaremos primeramente la presentación de productos inéditos en el mercado Sudamericano y de esta manera formaremos alianzas con asociados en los principales países de la región: Buenos Aires, Santiago y Montevideo. Para que esta empresa tenga éxito es necesario también definir las herramientas más efectivas de marketing digital a ser sea usadas en la relación con los clientes.

\subsection{Objetivos específicos de la investigación}

- Conocer las herramientas de marketing digital para una empresa $100 \%$ virtual

- Crear el conocimiento sobre cuáles son los elementos estratégicos para hacer negocios a través de Internet en América del Sur. 
- Desarrollar el proyecto de marketing digital para la creación de una empresa $100 \%$ virtual en lo que respecta a la propaganda y divulgación de los servicios de la empresa.

\subsection{Metodología}

La metodología que se utilizará para el desarrollo de este trabajo de tesis será a través de un estudio de caso, mediante el estudio de las mejores herramientas y estrategias de marketing digital para Sudamérica. La técnica de investigación que se utilizará es por medio de estudios exploratorios utilizándose de la información pre-existente.

Para esta investigación se utilizaron fuentes secundarias, mencionadas en la bibliografía, como libros, estadísticas, periódicos, estudios anteriores, revistas especializadas y sitios en Internet. Fueron usadas obras en tres idiomas diferentes: inglés, español y portugués. Se conceptualizará el marketing y sus principales herramientas a partir de la presentación de un breve relato histórico, explicando con mayor precisión y detalle como las herramientas de marketing digital pueden contribuir en la creación de una empresa $100 \%$ virtual. Todo esto considerando las diferencias culturales y las diferentes formas de hacer negocios digitales en América Latina.

\subsection{Justificación de la elección del tema}

Trabajo en el área de gestión de proyectos hace más de 25 años y verifiqué que tiene una gran escasez de herramientas prácticas y eficaces, basadas en Internet, para auxiliar en la gestión de la administración de los proyectos. Entiendo que América del Sur se está desarrollando de forma muy rápida en los últimos años y este desarrollo genera más y más proyectos.

Debido a ello, mi idea es crear una empresa que actuará con el enfoque en la prestación de servicios de consultoría y capacitación en gerenciamiento de proyectos. Para hacer la promoción y divulgación de los productos de la empresa va a desarrollar una herramienta, con soporte de marketing digital, es decir, no usaremos ningún otro medio de divulgación de la empresa que no sea medios digitales.

Se trata de un caso real que deseo llevar adelante personalmente y registrar la patente de esta herramienta como una nueva metodología. La tesis me ayudará en este trabajo 
indicando las mejores formas y las mejores prácticas que deben ser adoptadas en la creación de este servicio / proyecto.

\section{Herramientas de marketing digital}

El marketing digital utiliza efectivamente Internet como medio de comunicación entre personas y empresas. Normalmente comprende comunicación, publicidad y propaganda para hacer que las personas y empresas conozcan los productos y servicios que desea vender al mercado. Para el uso efectivo de Internet es necesario crear una estrategia de marketing y asegurarse que la misma sea efectiva. Para la creación de esta estrategia de marketing primero mostraremos cuales son las herramientas disponibles que pueden ser usadas de forma eficiente. Tales herramientas serán mostradas a continuación:

\begin{tabular}{|c|c|}
\hline Herramienta & Descripción \\
\hline Google & $\begin{array}{l}\text { Google AdWords para gerenciar links patrocinados que sirven para anuncios, } \\
\text { Google AdServer para la incorporación de anuncios y Google Analytics para } \\
\text { analizar las visitas a nuestro sitio web. }\end{array}$ \\
\hline Websites & $\begin{array}{l}\text { Para mostrar nuestro producto o servicio a nuestros clientes de forma directa y } \\
\text { objetiva. Así el Website es la puerta de entrada a nuestra empresa para la } \\
\text { realización de negocios virtuales. }\end{array}$ \\
\hline Blogs & Para escribir artículos que generen valor añadido a los clientes \\
\hline Mashups & Mashups es la reutilización de parte de otros sitios web en nuestro sitio web. \\
\hline Widgets & $\begin{array}{l}\text { Widgets son aplicaciones que ejecutan libremente en diversas plataformas. Un } \\
\text { ejemplo de Widgets es cuando mostramos en nuestro sitio posts del Twitter o } \\
\text { del Facebook }\end{array}$ \\
\hline Email & $\begin{array}{l}\text { A través de email podemos crear listas de distribución con nuestros potenciales } \\
\text { y actuales clientes para enviar promociones, presentaciones de novedades y } \\
\text { newsletter. }\end{array}$ \\
\hline $\begin{array}{l}\text { Motores de } \\
\text { búsqueda en } \\
\text { internet }\end{array}$ & $\begin{array}{l}\text { Son herramientas usadas en marketing de búsqueda. SEM (Search Engine } \\
\text { Marketing) mejorar la estructura y los textos de un sitio web con el objetivo de } \\
\text { volverlo más visible y mejorar su posicionamiento en las herramientas de } \\
\text { búsqueda. Utiliza técnicas y actividades que llamamos SEO (Search Engine } \\
\text { Optimisation). EI SEM (Search Engine Marketing) es una estrategia online de } \\
\text { marketing que busca aumentar la visibilidad del sitio web construyendo una }\end{array}$ \\
\hline
\end{tabular}




\begin{tabular}{|c|c|}
\hline ienta & Descripción \\
\hline & $\begin{array}{l}\text { marca online para la empresa. Las herramientas más comunes que podemos } \\
\text { usar para SEM (Search Engine Marketing) es el Google Adwords, Microsoft } \\
\text { adCenter y Yahoo Search Marketing. Es importante tener en mente que para } \\
\text { optimizar un sitio usando SEO (Search Engine Optimisation) es necesario que } \\
\text { tengamos contenido para eso, caso contrario no conseguiremos los efectos } \\
\text { deseados. Por lo tanto el SEO (Search Engine Optimisation) es una } \\
\text { herramienta usada para marketing de búsquedas que busca el incremento de } \\
\text { los accesos al sitio web y es visitado a través del Search Engine Ranking } \\
\text { Positions (SERP). En Google por ejemplo, cuanto más su sitio web aparece en } \\
\text { la primera página, más visitantes recibirá de los buscadores. El SEO (Search } \\
\text { Engine Optimisation) ayudará a aumentar naturalmente la vista del mismo. }\end{array}$ \\
\hline $\begin{array}{l}\text { Social Media } \\
\text { Marketing } \\
\text { (SMM) }\end{array}$ & $\begin{array}{l}\text { Social Media Marketing (SMM) es el proceso en el cual nos basamos en las } \\
\text { herramientas de media social para divulgar nuestra marca, productos y } \\
\text { servicios. Como herramientas de media social podemos citar: Facebook, Orkut, } \\
\text { Linkdln, MySpace, Twitter, Google+, Pinterest y Wikipedia. }\end{array}$ \\
\hline Ban & $\begin{array}{l}\text { Son inserciones de publicidades en sitios web o páginas web, que pueden } \\
\text { contener o no animaciones, interacción, sonido, vídeo y otros recursos }\end{array}$ \\
\hline $\begin{array}{l}\text { Podcast e } \\
\text { videocast }\end{array}$ & $\begin{array}{l}\text { Podcast es el nombre dado a la publicación de un archivo de audio digital } \\
\text { normalmente distribuido en el formato MP3 y que queda disponible para que los } \\
\text { usuarios del sitio web escuchen ese audio. La actualización del Podcast puede } \\
\text { ser hecha a través de mecanismos RSS. Videocast tiene la misma aplicación del } \\
\text { Podcast, sólo que al contrario de un archivo de audio publicamos un vídeo. }\end{array}$ \\
\hline Clipping & $\begin{array}{l}\text { Seleccionamos un conjunto de noticias a partir de diversos sitios web y los } \\
\text { concentramos en un único lugar, de esta manera llamando la atención de } \\
\text { nuestro cliente }\end{array}$ \\
\hline $\begin{array}{l}\text { Game } \\
\text { marketing }\end{array}$ & $\begin{array}{l}\text { Con la evolución de las tecnologías Java y Flash podemos crear juegos cuyo } \\
\text { propósito sea de atraer clientes }\end{array}$ \\
\hline $\begin{array}{l}\text { Medios } \\
\text { Sociales }\end{array}$ & $\begin{array}{l}\text { Cuando deseamos generar un vídeo o imágenes virales para un determinado } \\
\text { propósito podemos usar los medios de comunicación social como el Youtube o } \\
\text { Flickr. En este caso creamos nuestro vídeo o imagen con el contenido deseado } \\
\text { y hacemos la publicación de este contenido en los medios de comunicación } \\
\text { social. }\end{array}$ \\
\hline Monitoreo & רos trabajando con informática y marketing digital tenemos la \\
\hline
\end{tabular}




\begin{tabular}{|l|l|}
\hline Herramienta & Descripción \\
\hline & $\begin{array}{l}\text { posibilidad de medir los resultados que estamos alcanzando con nuestra } \\
\text { estrategia de marketing digital. Usaremos la herramienta PostX } \\
\text { (www.postx.com.br) y el monitoreo de los medios de comunicación social, } \\
\text { además de medir los resultados, mide también la imagen de la marca, opinión } \\
\text { de los consumidores, problemas con los productos, etc. }\end{array}$ \\
\hline App Stores & $\begin{array}{l}\text { Una forma de divulgar una organización puede ser a través del desarrollo de } \\
\text { una aplicación que es distribuida gratuitamente para varios dispositivos } \\
\text { pudiendo inclusive ser dispositivos móviles tales como Smartphones, Tablets, } \\
\text { etc. }\end{array}$ \\
\hline
\end{tabular}

Fuente: Vaz, Conrad Adolpho. (2011), Reed, John. (2012) Marketing Online 


\section{Elementos estratégicos para hacer negocios a través de internet}

Según Claudio Torres ${ }^{6}$, debemos adoptar una visión basada en el comportamiento del consumidor, es decir, debemos ponerlo en el centro de nuestros principios. Negocios y comercialización deben centrarse en los consumidores, ya que es la razón de ser de una organización. Por lo tanto si adoptamos un modelo de marketing digital basado en el cliente como centro, la oportunidad de tener éxito en este modelo será muy grande. Otro punto que debemos considerar es que las técnicas de marketing offline que se basan en el comportamiento del consumidor también son aplicaciones en marketing digital. Basado en este concepto, según Claudio Torres ${ }^{6}$, la siguiente tabla se utilizará para la definición de estrategias que podemos adoptar para hacer la gestión de marketing digital de nuestra organización.

\begin{tabular}{|l|l|l|l|}
\hline $\begin{array}{l}\text { Estrategia de } \\
\text { Marketing }\end{array}$ & $\begin{array}{l}\text { Estrategia de } \\
\text { Marketing } \\
\text { digital }\end{array}$ & $\begin{array}{l}\text { Acciones tácticas } \boldsymbol{y} \\
\text { operacionales }\end{array}$ & $\begin{array}{l}\text { Tecnologías } \boldsymbol{y} \\
\text { plataformas empleadas } \\
\text { actualmente }\end{array}$ \\
\hline $\begin{array}{l}\text { Comunicación } \\
\text { corporativa } \\
\text { Relaciones públicas }\end{array}$ & $\begin{array}{l}\text { Marketing de } \\
\text { contenido }\end{array}$ & $\begin{array}{l}\text { Generación de contenido } \\
\text { Marketing de } \\
\text { Buscadores }\end{array}$ & $\begin{array}{l}\text { Blogs } \\
\text { SEO/SEM }\end{array}$ \\
\hline $\begin{array}{l}\text { Marketing de } \\
\text { relacionamiento }\end{array}$ & $\begin{array}{l}\text { Marketing en } \\
\text { los medios de } \\
\text { comunicación } \\
\text { social }\end{array}$ & $\begin{array}{l}\text { Acciones en redes } \\
\text { sociales } \\
\text { Acciones con bloggers }\end{array}$ & $\begin{array}{l}\text { Orkut, Twitter, Facebook, } \\
\text { YouTube, Linkedln, etc }\end{array}$ \\
\hline $\begin{array}{l}\text { Marketing directo } \\
\text { marketing }\end{array}$ & $\begin{array}{l}\text { Newsletters } \\
\text { Promociones } \\
\text { Lanzamientos }\end{array}$ & $\begin{array}{l}\text { E-mail } \\
\text { SMS }\end{array}$ \\
\hline $\begin{array}{l}\text { Publicidad y } \\
\text { de guerrilla }\end{array}$ & Marketing viral & $\begin{array}{l}\text { Publicaciones de } \\
\text { videos, animaciones y } \\
\text { músicas } \\
\text { Publicación de widgets }\end{array}$ & $\begin{array}{l}\text { Redes sociales } \\
\text { YouTube } \\
\text { Widgets virales }\end{array}$ \\
\hline $\begin{array}{l}\text { Publicidad y } \\
\text { propaganda } \\
\text { Branding }\end{array}$ & $\begin{array}{l}\text { Publicidad } \\
\text { online }\end{array}$ & $\begin{array}{l}\text { Podcast y Videocast } \\
\text { Widgets } \\
\text { Juegos online }\end{array}$ & $\begin{array}{l}\text { Sitios web y Blogs } \\
\text { Medios de comunicación } \\
\text { sociales } \\
\text { Google AdWords }\end{array}$ \\
\hline $\begin{array}{l}\text { Investigación de } \\
\text { mercado } \\
\text { Branding }\end{array}$ & $\begin{array}{l}\text { Investigación } \\
\text { online }\end{array}$ & $\begin{array}{l}\text { Monitoreo de marca y } \\
\text { medios de comunicación }\end{array}$ & $\begin{array}{l}\text { Google } \\
\text { Redes sociales } \\
\text { Clipping }\end{array}$ \\
\hline
\end{tabular}

Fuente: Torres, Claudio. (2009) A Biblia do Marketing Digital. São Paulo: Novatec , pag. 68 y 69

La interacción entre las diversas acciones tácticas y operativas para marketing digital puede ser vista en el siguiente diseño que muestra la visión amplia del marketing digital en Internet e indica la estrategia que adoptaremos. 


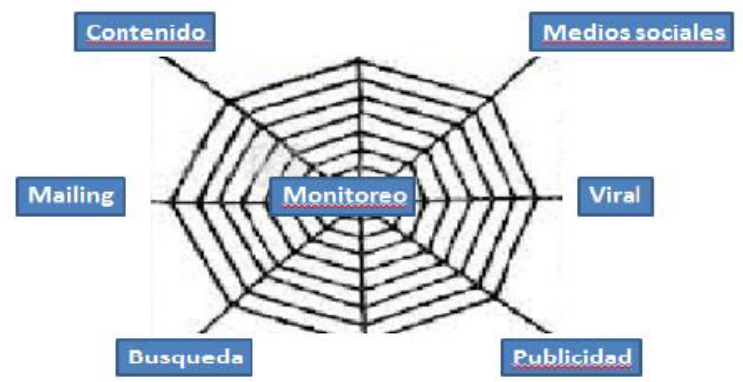

La figura que se muestra a continuación ilustra e indica la necesidad de coordinación e interacción entre las acciones estratégicas, es decir, jamás debemos pensar en apenas una cajita aislada.

Fuente: Torres, Claudio. (2009) A Biblia do Marketing Digital. São Paulo: Novatec , pag. 71

Para hacer marketing necesitamos de visión holística que trabajaremos desde este momento con el fin de mostrar la estrategia que será adoptada, así como las herramientas que vamos a utilizar con el fin de alcanzar el objetivo que es la creación de una empresa totalmente virtual para proporcionar servicios de gestión de proyectos. Serán servicios de consultoría, capacitación, implementación de Project Management Office (PMO) y gestión de proyectos que podrán ser ofrecidos según la demanda del cliente.

La estrategia que adoptaremos es la indicada por Conrado Adolpho, llamada "Los 8P's del Marketing Digital" ${ }^{8}$. Esta estrategia estará basada en el marketing convencional adecuado para marketing digital y teniendo como centro al consumidor pues él es quien determina cómo deben ser los productos y/o servicios de una empresa.

\section{1 - INVESTIGACIÓN}

La investigación es la base de otros elementos de la planificación, ya que tiene como objetivo descubrir acerca de nuestros mercados y el comportamiento de los mismos. Desde el descubrimiento de estos mercados y su comportamiento, podemos trazar nuestra estrategia de marketing digital.

Lo primero en que debo preocuparme es como debo comunicar a nuestro cliente potencial, es decir, cuál es el lenguaje que utilizo, sus valores, deseos y experiencias. También debo recordar que en Internet, debido a las formas de comunicación disponibles para externalizar sus necesidades, debo aprovecharla para conocerlo mejor.

La facilidad que el consumidor tiene para buscar y analizar en el mundo virtual hace son que realice todos los análisis antes de comprar un producto o servicio.

El primer punto que se debe considerar son las palabras que mayor rentabilidad traerán.

$\overline{{ }^{8} \text { Vaz, Conrad Adolpho. (2011) Os } 8 \text { Ps do marketing digital: o seu guia estratégico de marketing digital. São Paulo: Novatec }}$ 
La palabra clave es muy importante para que el mayor número posible de consumidores llegue hasta nuestra empresa. Esto se debe a que en el mundo virtual si el consumidor llegó hasta mí es porque él ya ha realizado un estudio comparado y encontró interesante mi producto o servicio, y esto contribuirá para que una buena parte de la venta (quizás el $50 \%$ ) se haya realizado. Esto significa que cuando el consumidor llegó a mi empresa, ya pasó por diversos filtros y comparaciones con los competidores.

Hoy en día con el advenimiento de Internet, se puede armar un sitio web bien estructurado y empezar la operación a través de la web mostrando los productos y servicios.

Google es el buscador más utilizado y se debe recordar que la mayoría de las búsquedas realizadas en Internet están directamente relacionadas con la vida real. Así que Google es un gran apoyo para llevar a cabo búsquedas, por ello se usará la herramienta llamada Google Insights for Search para ayudar en la investigación de comportamiento de los consumidores potenciales.

El objetivo es entender más allá de la conducta del consumidor, elegir las palabras claves más apropiadas para el negocio, porque si el sitio web es encontrado en la primera posición del Google, tendrá un tráfico importante para iniciar bien el trabajo de marketing digital. El Google Insights for Search es una herramienta de Search Engine Optimisation (SEO) que ayudará a comprender el perfil de nuestro cliente.

Usando el buscador de Google, se llega a la conclusión de que las palabras-clave utilizadas dieron buen resultado. Según se muestra en los siguientes gráficos (Investigación en portugués):

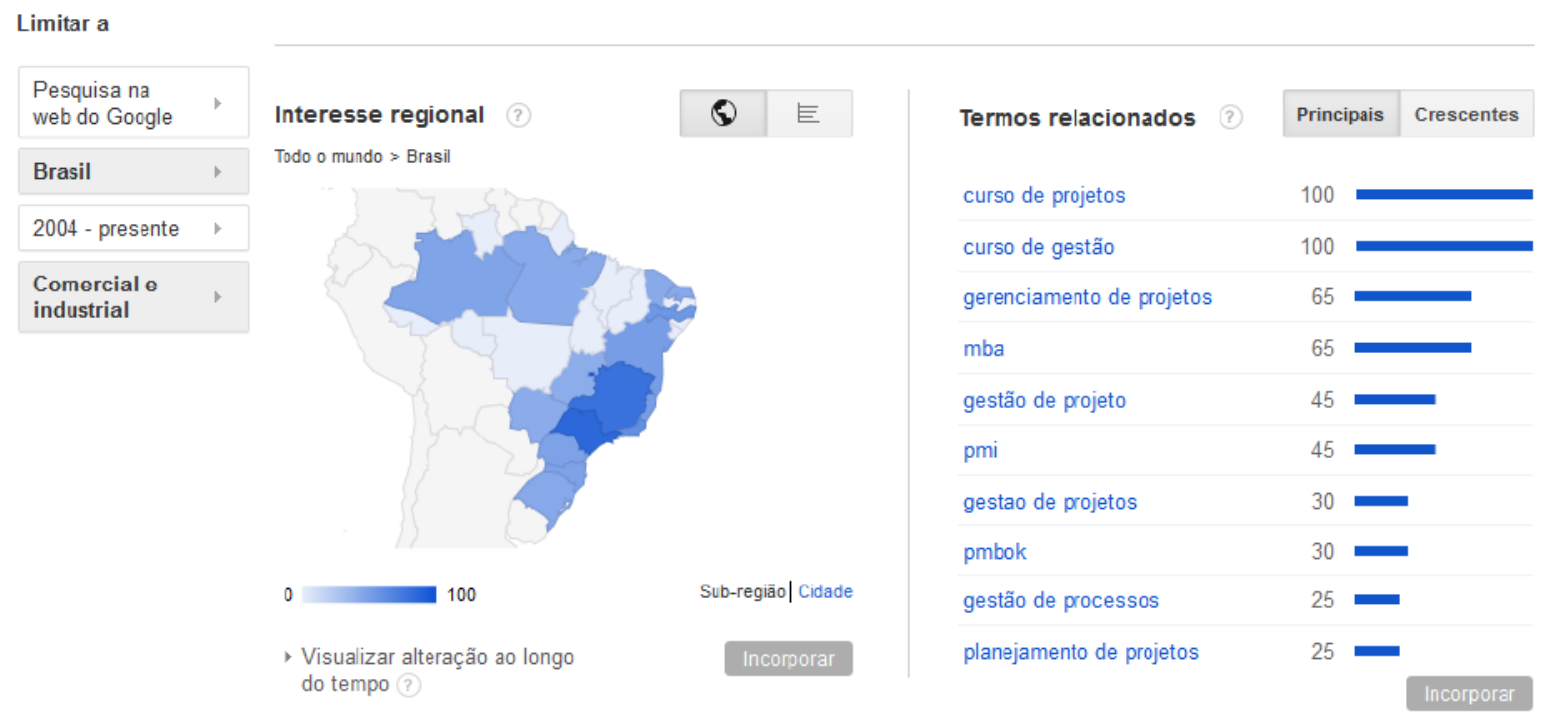


Investigación en español:
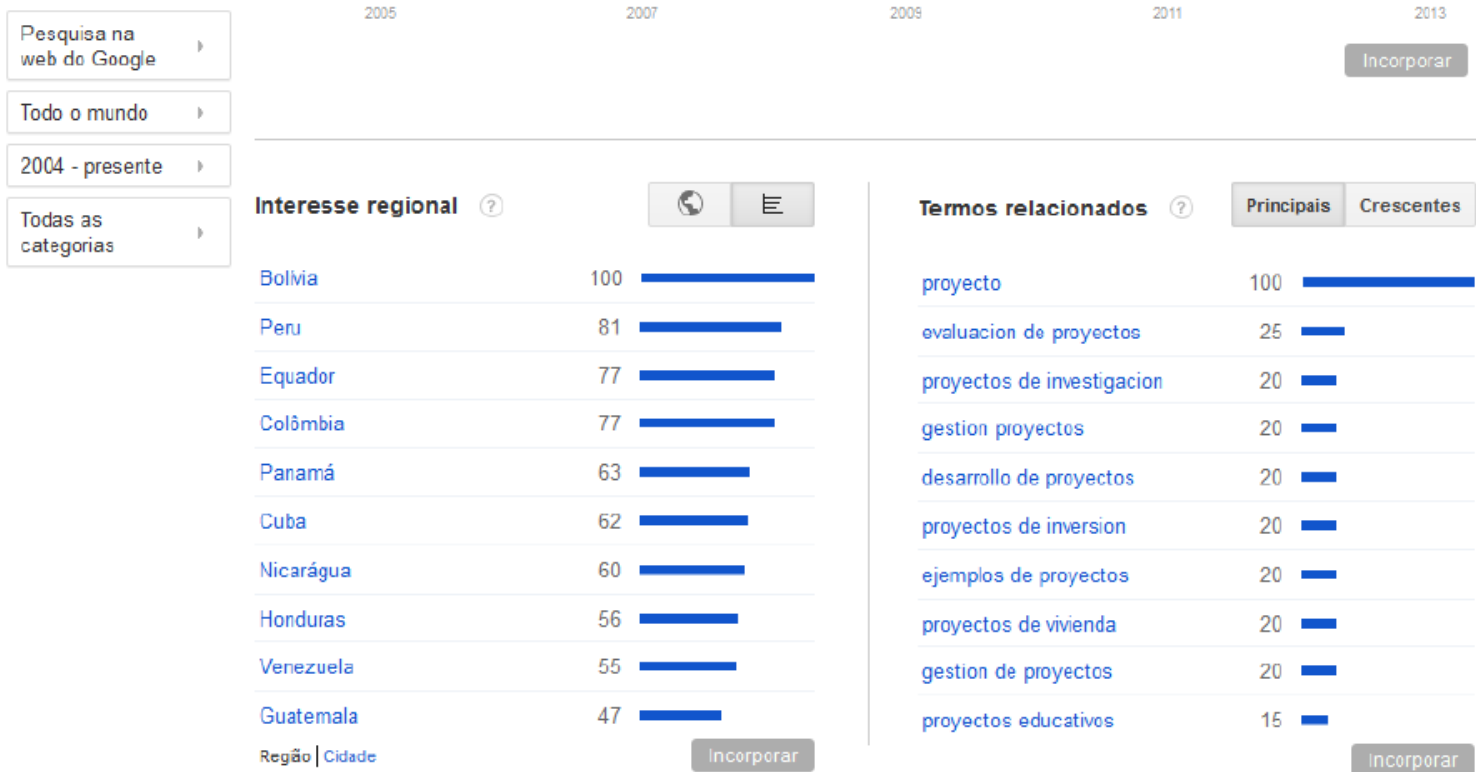

Fuente: Google Insights for Search, http://www.google.com/trends/

Con estos datos obtenidos en Google Insights for Search, llegamos a la conclusión de que nuestras palabras-clave son buenas.

Esto también queda demostrado por el comportamiento de búsqueda de palabras clave de Google AdWords. No se muestra toda la lista generada ya que el objetivo es mostrar sólo que las palabras clave son buenas.

\begin{tabular}{|l|l|l|l|}
\hline & Concurrencia & $\begin{array}{l}\text { Investigaciones } \\
\text { globales } \\
\text { mensuales }\end{array}$ & $\begin{array}{l}\text { Investigaciones } \\
\text { locales mensuales } \\
\text { (Brasil) }\end{array}$ \\
\hline gestión de proyectos & 0,64 & 110000 & 110000 \\
\hline administración de proyectos & 0,6 & 110000 & 110000 \\
\hline $\begin{array}{l}\text { curso de administración de } \\
\text { proyectos }\end{array}$ & 0,96 & 8100 & 8100 \\
\hline administración de proyectos & 0,66 & 90500 & 90500 \\
\hline administración de proyecto & 0,66 & 90500 & 90500 \\
\hline pmbok & 0,14 & 301000 & 49500 \\
\hline curso de proyecto & 0,51 & 49500 & 49500 \\
\hline
\end{tabular}




\begin{tabular}{|l|l|l|l|}
\hline $\begin{array}{l}\text { Pmi (Project Mananagement } \\
\text { International) }\end{array}$ & 0,2 & 1220000 & 49500 \\
\hline proyectos de gestión & 0,64 & 110000 & 110000 \\
\hline Administración de proyecto & 0,66 & 110000 & 90500 \\
\hline
\end{tabular}

Fuente: Google Insights for Search, http://www.google.com/trends/

Llegamos a la conclusión de que las palabras claves son buenas y permiten ser encontrados por aquellos que comprarán el producto o servicio. Sin duda se elgirán las palabras principales del negocio:

* PMI (Project Management Institute), PMP (Project Management Professional), PMBOK (Project Management Body of Knowledge)

* Proyectos, Gestión de Proyectos, Administración de Proyectos

* Capacitación en Proyectos, Coach en Proyectos

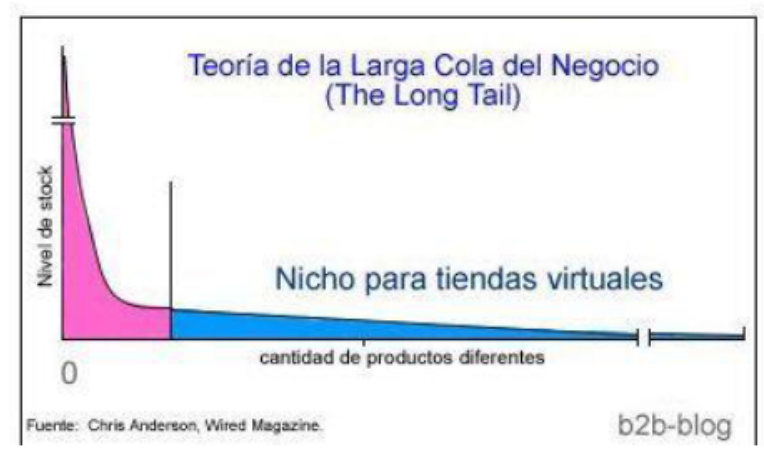

Fuente: Anderson, Chris. "The Long Tail" Wired, October 2004.
Cuando se esté produciendo el contenido del sitio y el material, sin duda se prestará atención para usar estas palabras -clave para que sean encontradas por los clientes. La intención es hacer uso de la Teoría de la Larga Cola discutida en el libro de Chris Anderson ${ }^{10}$, pues queremos usar la Web para llegar a clientes específicos según se muestra en el diagrama al lado:

\section{2- Planificación}

La misión crítica del sitio web de la empresa es:

- Venta de servicios de consultoría en gestión de proyectos

- Venta de capacitación en gestión de proyectos

- Captura de e-mails de nuevos clientes

${ }^{10}$ Anderson, Chris. (2008)The Long Tail. Estados Unidos: Hyperion Books 
Las metas que se desean alcanzar están basadas en los objetivos a cumplir:

- Tener en el registro del sitio web en 1 año más de 10.000 direcciones de e-mails para e-mail marketing

- Conseguir en 1 año cerrar contratos de por lo menos 3 consultorías

- Prestar servicios de capacitación en el primer año para dos Facultades en Brasil

Como se actuará en la planificación del marketing digital:

\begin{tabular}{|c|c|}
\hline Pregunta & Respuesta \\
\hline En qué negocio estamos & Consultoría y capacitación en Administración de Proyectos \\
\hline \begin{tabular}{|l} 
Clientes en nuestro mercado \\
\end{tabular} & $\begin{array}{l}\text { Empresas y personas físicas que necesitan de soporte y } \\
\text { capacitación para administrar sus proyectos }\end{array}$ \\
\hline Segmentación del mercado & $\begin{array}{l}\text { Empresas de pequeño y medio porte, personas físicas que } \\
\text { desean capacitarse y escuelas que ofrecen capacitación en } \\
\text { proyectos }\end{array}$ \\
\hline $\begin{array}{l}\text { Necesidad de cada } \\
\text { segmento }\end{array}$ & $\begin{array}{l}\text { Empresas: consultoría y uso de herramientas } \\
\text { Personas físicas: capacitación en gestión de proyectos y } \\
\text { preparación para certificación. Escuelas: servicios de profesor }\end{array}$ \\
\hline $\begin{array}{l}\text { Que debemos probar para } \\
\text { cada segmento }\end{array}$ & $\begin{array}{l}\text { Empresas: que somos capaces de proveer consultoría } \\
\text { Personas físicas: que nuestra capacitación alcance sus } \\
\text { necesidades } \\
\text { Escuelas: que tenemos el know-how para impartir con calidad }\end{array}$ \\
\hline $\begin{array}{l}\text { Posicionamiento de la } \\
\text { empresa }\end{array}$ & $\begin{array}{l}\text { Empresas de pequeño y mediano porte, Personas físicas } \\
\text { Facultades que poseen MBA en Proyectos }\end{array}$ \\
\hline Comunicación & $\begin{array}{l}\text { Todos los que utilizan y trabajan con administración de proyectos } \\
\text { usan la tecnología de la información (TI) como medio. Luego se } \\
\text { usarán las herramientas de marketing digital para relacionarse } \\
\text { con los clientes }\end{array}$ \\
\hline Expansión por segmento & $\begin{array}{l}\text { Empresas: } 2 \text { nuevos clientes por año } \\
\text { Personas físicas: } 50 \text { nuevos alumnos por año } \\
\text { Escuelas: } 15 \text { nuevos grupos por año }\end{array}$ \\
\hline $\begin{array}{l}\text { Tamaño inicial de la } \\
\text { empresa }\end{array}$ & $\begin{array}{l}\text { La empresa estará constituida inicialmente por un profesional } \\
\text { técnico y un profesional de gestión. }\end{array}$ \\
\hline
\end{tabular}

Fuente: Elaboración propia

Finalmente se hará la planificación para la implementación del proyecto. 


\subsection{1 - Segmentación del mercado}

$\checkmark$ Empresas de pequeño y mediano porte

$\checkmark$ Personas físicas que desean capacitarse

$\checkmark$ Escuelas que ofrecen capacitación en proyectos

$\checkmark$ Empresas de grande tamaño

$\checkmark$ Coaching

\subsection{2 - Beneficio para cada segmento}

$\checkmark$ Empresas de pequeño y mediano porte: consultoría y capacitación para mejorar y ganar productividad en la gestión de proyectos

$\checkmark$ Personas físicas que desean capacitarse en proyectos: realización de las capacitaciones necesarias para la certificación PMP y adquisición de conocimientos personales

$\checkmark$ Escuelas que ofrecen capacitación en proyectos: aplicación de la capacitación siguiendo el programa y cronograma indicado por la escuela.

\subsection{3- Factores críticos de éxito del negocio}

$\checkmark$ Garantizar que las personas que llegan al sitio web realmente estén interesados en el trabajo ofrecido. Esto se consigue por medio de la adopción de palabras clave.

$\checkmark$ Credibilidad que llevará también a un posicionamiento fuerte y adecuado para el público potencial. Ese posicionamiento será basado en el eslogan: "Sólida experiencia en administración y capacitación en proyectos."

\subsection{4- Posicionamiento adecuado para estos segmentos escogidos}

Tener disponible un sitio web con contenido altamente relevante, con materiales para descargar y con un framework online para que el cliente pueda realizar sus tests y ganar confianza en los servicios prestados por la empresa. Para cursos presenciales, crear material de calidad y contenido relevante con el objetivo de atender las demandas de las empresas, potenciales contratantes. 


\subsection{5- Equipo que trabajará en el departamento de Internet}

\begin{tabular}{|c|c|}
\hline Función & Estrategia \\
\hline Gerente de marketing digital & $\begin{array}{l}\text { Será la persona de gestión de la empresa y ella seguirá el uso de } \\
\text { las herramientas de marketing digital definidas para la empresa. }\end{array}$ \\
\hline $\begin{array}{l}\text { Analista de Search Engine } \\
\text { Optimizer (SEO) }\end{array}$ & Será también la persona de gestión de la empresa. \\
\hline $\begin{array}{l}\text { Analista de medios de } \\
\text { comunicación social }\end{array}$ & Será también la persona de gestión de la empresa. \\
\hline Analista de métricas & $\begin{array}{l}\text { Será un trabajo conjunto entre gestión y técnica para evaluar si los } \\
\text { objetivos propuestos están siendo alcanzados }\end{array}$ \\
\hline Desarrollador & Será contratada una empresa para desarrollar el sitio web. \\
\hline Designer de interfaces & Será la misma empresa contratada para el desarrollo. \\
\hline Gestor de la empresa & Será un comité entre el gestor administrativo y el gestor técnico. \\
\hline
\end{tabular}

Fuente: Elaboración propia

\subsection{6- Misiones críticas del sitio web}

* Conseguir que se registren en el sitio web durante el primer 1 año más de 10.000 direcciones de e-mails para e-mail marketing

* Tener como mínimo 2 empresas usando nuestro framework el primer año.

* Tener registrados en la primera operación más de 500 alumnos de facultades que usarán los recursos del sitio web como framework y descargas.

* Alcanzar el número de 20.000 accesos en el primer año de operación.

\subsection{7- Alcance del site}

Será un sitio web en donde se tendrá las siguientes posibilidades:

* Presentación institucional de la empresa, sus productos y servicios.

* Un área conteniendo el framework de gestión de proyectos propuesto por la empresa.

* Un área para que el usuario se registre para tener acceso a descargas.

* Un área de descargas con control de acceso.

* Un área de artículos, Podcasts y Videocasts.

* Un área para que el usuario envíe sus opiniones y saque sus dudas.

* Un área para hablar sobre herramientas de mercado. 
* Un área de novedades. En esta área el usuario podrá compartir también las novedades del Facebook y Twitter.

* Un área conteniendo links útiles.

* Un área donde el usuario se registra para recibir la newsletter.

\subsection{8- Wireframe del sitio web}

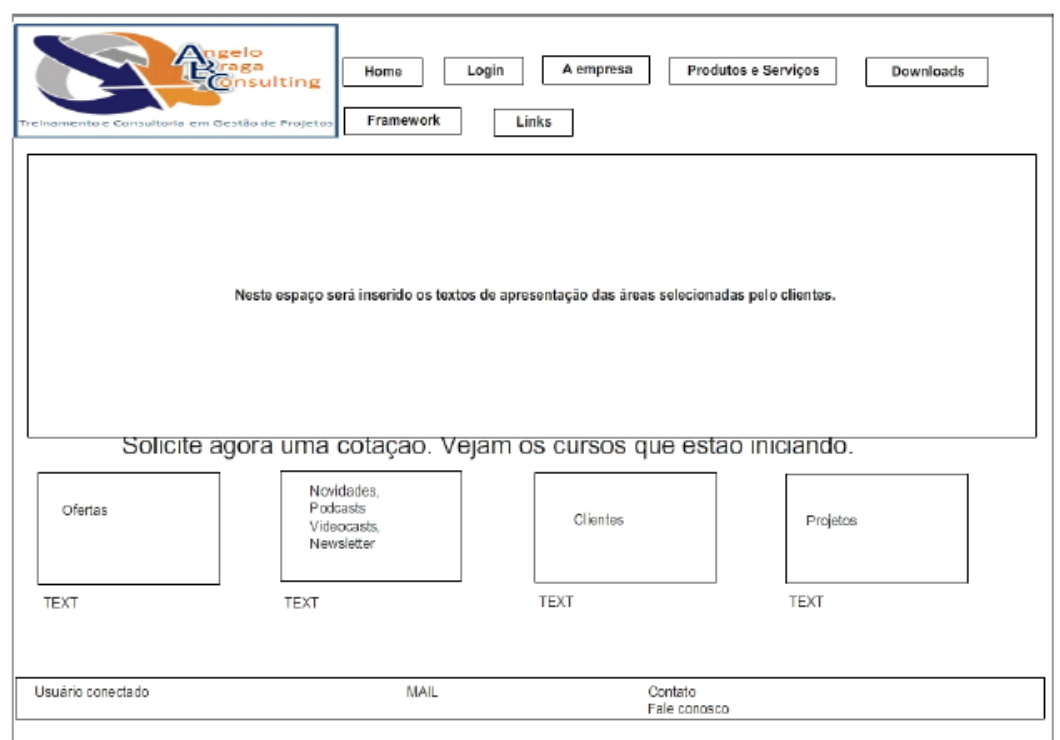

Fuente: Elaboración propia

La descripción del sitio web se realizará en el proyecto para la creación de la empresa.

\subsection{9 - Layout y contenido del sitio web}

El layout y contenido del sitio web estará orientado hacia un contenido basado en texto, imágenes y vídeos con alto contenido técnico porque nuestro público objetivo es técnico buscando perfeccionar sus conocimientos y en busca de diferenciales competitivos.

\subsubsection{0- Contenido para los medios de comunicación sociales}

Se desea entrar sólo en Facebook, MySpace, Linkedln, Youtube, Flickr y Twitter, medios de comunicación social, interacción basada en la cooperación de redes sociales de nicho en un primer momento. Por lo tanto vamos a desarrollar una página de la compañía en Facebook con información sobre los cursos, artículos y otras informaciones relevantes para el cliente. En Twitter diariamente buscaremos la publicación de enlaces que contienen nuestras novedades y temas tratados en el newsletter. 


\subsubsection{1- Contenido que será generado por el consumidor}

Es esperable que el consumidor presente dudas y preguntas sobre los cursos, capacitaciones, coaching y consultorías y también ingresará sus datos en el sitio web para hacer descargas de artículos y documentos.

\subsubsection{2- Promociones para lanzar la empresa en Internet}

Para que se conozca la marca se trabajará con los sitios web de compras colectivas que ofrecen descuentos en los cursos que se ofrecen al público en general. Por lo tanto, se reducirán los precios en un principio, pero se ganará en número de alumnos matriculados, que es el objetivo inicial. Los sitios web que se trabajarán inicialmente son: Peixe Urbano Brasil, Groupon Brasil, Clickon Argentina, Saveme Brasil y Groupon Argentina. ${ }^{11}$

\subsubsection{3- Campañas de $e$-mail marketing}

Se realizará una campaña semanal donde se llamará la atención de los clientes y posibles clientes sobre las novedades que se lanzarán al mercado.

\section{3 - Producción}

Para construir el sitio web de calidad se deben tener en cuenta los siguientes temas: marketing, tecnología, texto, layout, usabilidad y persuasión.

Así que para preparar el sitio web y construirlo al menos en cuatro áreas de la empresa deben estar presentes: el marketing, la tecnología, el webdesigner (departamento que produce el contenido del sitio web) y el equipo de diseño responsable. La usabilidad y la optimización del sitio para ser encontrado son importantes pues si el usuario no encuentra nuestro sitio web, o si lo encuentra pero tiene problemas en usarlo, desde luego, no la usará.

Por lo tanto, en el trabajo de desarrollo del sitio web se tendrán en cuenta las funciones:

\footnotetext{
${ }^{11}$ www.peixeurbano.com.br, www.groupon.com.br, www.clickon.com.ar, www.saveme.com.br e www.grupon.com.br.
} 


\begin{tabular}{|l|l|}
\hline Equipo & Función \\
\hline Marketing & Define las palabras-clave que el sitio web usará en condiciones de optimización \\
\hline Contenido & $\begin{array}{l}\text { Escribirá las palabras-clave e insertará las imágenes y animaciones en los lugares } \\
\text { correctos y con las cantidades adecuadas. }\end{array}$ \\
\hline Design & $\begin{array}{l}\text { Desarrollará la interface que permita que el contenido y las funcionalidades sean } \\
\text { leídas por Google. }\end{array}$ \\
\hline Tecnología & $\begin{array}{l}\text { Trasformará todo lo que fue descrito arriba en realidad. } \\
\text { Deberá preocuparse también con el tiempo de carga del sitio web y por último } \\
\text { invertir en la seguridad del sitio web debido al crecimiento de la ciberdelincuencia. }\end{array}$ \\
\hline
\end{tabular}

Fuente: Elaboración propia

Se deberá-crear un esqueleto de página llamado wireframe que mostrará, obviamente sin ningún layout, que elementos debe contener en cada página, con comentarios y la prioridad de cada uno de ellos. El wireframe se muestra en la sección 3.2.8 y el resto se muestra en proyecto del sitio web en sí.

El sitio web debe ser sobrio y diseñado con buen gusto para transmitir credibilidad. Un sitio web hermoso transmite confianza al consumidor y aumenta la tasa de conversión de usuarios. No se debe confundir la belleza con la complejidad. La simplicidad en su mayoría tiene que ver con la belleza. Por lo tanto, se debe tratar de construir un sitio web más "clean", dando espacio para el texto presentado, es decir, textos con espacios en blanco.

En el sitio web se utilizará un login para iniciar la sesión y permitir el acceso directo a un área específica de contenido y descargas.

Se conocen los siguientes tipos de páginas:

\begin{tabular}{|l|l|}
\hline Tipo de página & Descripción \\
\hline Institucional & Hablan sobre la empresa (presentación). \\
\hline $\begin{array}{l}\text { Generar relacionamiento con } \\
\text { el público deseado }\end{array}$ & $\begin{array}{l}\text { Son las páginas más importantes del sitio web pues hablan sobre } \\
\text { el consumidor y no sobre la empresa }\end{array}$ \\
\hline Destinadas a la misión crítica & $\begin{array}{l}\text { Llevan al consumidor a cumplir la misión crítica. Son las páginas } \\
\text { de formularios para comprar productos donde el consumidor hace } \\
\text { su opción de compra y realiza el pago. }\end{array}$ \\
\hline
\end{tabular}

Fuente: Elaboración propia 
En caso del sitio web se contruirán \& las siguientes páginas:

\begin{tabular}{|l|l|}
\hline Página & Función \\
\hline Principal & $\begin{array}{l}\text { Será la página de presentación del sitio. Obviamente estará llena de } \\
\text { palabras clave. }\end{array}$ \\
\hline Institucional & $\begin{array}{l}\text { Será la presentación de la empresa conteniendo misión, visión, valores y } \\
\text { principales clientes }\end{array}$ \\
\hline Login & $\begin{array}{l}\text { Será la página donde el usuario se registrará para obtener acceso } \\
\text { diferenciado al sitio web. }\end{array}$ \\
\hline Productos y Servicios & $\begin{array}{l}\text { Presentación de la cartera de productos y servicios, casos de éxito para } \\
\text { que los clientes puedan decidir si se es capaz o no de atender sus } \\
\text { necesidades. }\end{array}$ \\
\hline Downloads & $\begin{array}{l}\text { Área restricta donde el usuario sólo tendrá acceso a los cursos y } \\
\text { servicios que él contrató. }\end{array}$ \\
\hline Framework & $\begin{array}{l}\text { Framework conteniendo la metodología FAST PROJECT desarrollada } \\
\text { por la empresa. }\end{array}$ \\
\hline Links & $\begin{array}{l}\text { Links importantes de softwares y herramientas para GP (Gerencia de } \\
\text { Proyetos) }\end{array}$ \\
\hline Ofertas & Es una página que contendrá las promociones online. \\
\hline Novedades & $\begin{array}{l}\text { Contendrá una página destinada a la imprenta donde se colocatrán fotos } \\
\text { oficiales, informaciones de la empresa, informaciones del mercado, etc. }\end{array}$ \\
\hline Podcasts & Contendrá los podcasts producidos por la empresa. \\
\hline Videocasts & Contendrá los videocasts producidos por la empresa \\
\hline Newsletters & Contendrá las novedades de herramientas \\
\hline Clientes & $\begin{array}{l}\text { Área para que los usuarios dejen sus testimonios sobre los servicios } \\
\text { recibidos. Tendrá también un área para que hable con la empresa y } \\
\text { exprese sus opiniones, preocupaciones y reclamos. }\end{array}$ \\
\hline Referencias para clientes sobre los proyectos realizados por la empresa \\
\hline Se mostrarán los perfiles de la empresa en Facebook y Twitter. \\
\hline fuestos
\end{tabular}

Fuente: Elaboración propia

A continuación se describirán las características de la página principal: 


\begin{tabular}{|c|c|}
\hline Característica & escripción \\
\hline $\begin{array}{l}\text { URL (Uniform Resource } \\
\text { Locator) }\end{array}$ & $\begin{array}{l}\text { www.angelobraga.com.br : Será el dominio para el } \\
\text { posicionamiento del sitio web. Como es una empresa pequeña, sin } \\
\text { marca conocida, tendremos el nombre de su fundador como una } \\
\text { referencia en el mercado de gestión de proyectos. }\end{array}$ \\
\hline Título de la página Principal & capacitación y cons \\
\hline $\begin{array}{l}\text { Palabras clave a ser } \\
\text { utilizadas prioritariamente } \\
\text { en esa página }\end{array}$ & $\begin{array}{l}\text { Gestión de Proyectos, Gerencia de Proyectos, Gerenciamiento de } \\
\text { Proyectos, Capacitación en Gestión de Proyectos, } \\
\text { Consultoría en Gerenciamiento de Proyectos } \\
\text { Curso de gerenciamiento de proyectos }\end{array}$ \\
\hline $\begin{array}{l}\text { Textos de anclaje internos } \\
\text { de otras páginas } \\
\text { referenciando esta página }\end{array}$ & $\begin{array}{l}\text { Gestión de Proyectos, Gerencia de Proyectos, Consultoría en } \\
\text { Gerenciamiento de Proyectos } \\
\text { Consultoría en Gerenciamiento de proyectos }\end{array}$ \\
\hline Meta Tag Description & $\begin{array}{l}\text { Empresa de consultoría y capacitación en administración de } \\
\text { proyectos con amplia experiencia en todos los tipos de proyectos. } \\
\text { Capacitación para certificación PMP y cursos sobre demanda para } \\
\text { administración de proyectos. }\end{array}$ \\
\hline Meta & $\begin{array}{l}\text { Gestión de Proyectos, Consultoría en Administración de Proyectos, } \\
\text { Capacitación en Administración de Proyectos y } \\
\text { Capacitación en Gerenciamiento de Proyectos }\end{array}$ \\
\hline Título de la página principal & $\begin{array}{l}\text { Tendrá dos imágenes: la primera conteniendo el logotipo de la } \\
\text { empresa y la segunda una imagen ejecutiva con el texto: } \\
\text { "Consultoría y capacitación en Administración de Proyectos" }\end{array}$ \\
\hline $\begin{array}{l}\text { Destaques de la páginas } \\
\text { principal }\end{array}$ & $\begin{array}{l}\text { Tendremos imágenes de administración de proyectos } \\
\text { acompañados de los textos: } \\
\text { - ¿Ya imaginó su empresa usando una metodología ágil y segura } \\
\text { para administrar sus proyectos? } \\
\text { - ¿Ya se imaginó capacitado en todas las áreas del conocimiento } \\
\text { en Administración de Proyectos? Eso ampliará su currícula! } \\
\text { - ¿Usted necesita mejorar su forma de administración de } \\
\text { proyectos? ¿Está teniendo pérdidas financieras y problemas de } \\
\text { administración? Entonces es hora de revolucionar su modelo de } \\
\text { gestión! ¿Cómo? Contrate una consultoría de nuestra empresa. }\end{array}$ \\
\hline
\end{tabular}

Fuente: Elaboración propia 


\subsection{1- Desarrollo del contenido direccionado para el usuario}

Se debe considerar que los usuarios no quieren oír hablar de esta empresa y sí de lo que se puede ofrecer como productos o servicios para él y su empresa, es decir, el valor que se logrará generar para él y su empresa. En este caso se mostrará al usuario un framework de gestión de proyectos que podrá ayudarlo a mejorar en gestión de proyectos. Las capacitaciones lo ayudarán a incrementar su carrera y las consultorías lo ayudarán a operar de una mejor forma. Todo esto estará demostrado en el sitio web y lo que es relevante para el consumidor será mostrado en los podcasts, videocasts, newsletter y novedades.

Para construir este sitio web se seguirán algunas reglas basadas en las mejores prácticas. Ellas son:

* Título de la página destacado y claro.

* El primer parágrafo debe ser capaz de prender la atención del lector, es decir, deberá pasar el mensaje que todo el texto mostrará.

* Se escribirán siempre párrafos cortos para facilitar el diseño.

* Se insertarán muchas imágenes para mostrar los productos y servicios con el objetivo de facilitar el entendimiento de los textos presentados.

* Los puntos importantes serán destacados en listas con bullets.

* Si el texto presentado es largo se utilizarán subtítulos para que su lectura y comprensión sean facilitadas.

+ Obviamente se usarán hipertextos para facilitar la navegación y lectura del texto 


\section{4- Publicación}

La publicación del sitio web tiene que ver con el contenido que será presentado y se puede concluir que el trabajo del productor de textos necesita ser hecho con extrema habilidad y calidad.

\subsection{1- Contenido direccionado para una buena clasificación en Google}

El contenido es algo que genera valor y pueden ser considerados como contenido los siguientes elementos: imagen, texto, vídeo, sonido, testimonios, screencasts, audiobooks y slidecasts. Cuando se incerta una imagen se debe colocar un texto abajo explicando de que se trata para que el buscador la encuentre. De ahí se crea un término llamado de encontrabilidad.

Para que se tenga una buena encontrabilidad, se debe tener como base palabras claras, ya que las palabras forman parte de los criterios de búsqueda adoptada por los buscadores, especialmente en Google. El mecanismo de búsqueda crea un ranking de la página con base en las palabras encontradas durante la búsqueda y a partir de ahí crea una puntuación para el sitio web, puntuación que será la base de la encontrabilidad del sitio web. Eso significa que cuanto mejor sean las palabras-clave en el sitio web, meior será la encontrabilidad.

En este caso se generarán textos, siempre considerando las siguientes palabras-clave (observen que se adopta una lista un poco mayor que las definidas en la investigación):

\begin{tabular}{|l|}
\hline Palabras-clave \\
\hline curso de proyectos, curso de administración de proyectos \\
\hline gestión de proyectos, gerenciamiento de proyectos, gerencia de proyecto \\
\hline PMI, PMBOK (Project Management Body of Knowledge), PMP \\
\hline gestión de proyectos, administración de proyectos, gerencia de proyecto \\
\hline Proyectos, Capacitación en Proyectos, Coach en Proyectos \\
\hline
\end{tabular}

Fuente: Elaboración propia

Para que el sitio web aparezca en los resultados de los buscadores se necesita optimizarlo para tal utilizando el proceso de SEO. Así, lo que se debe optimizar en nuestro texto está detallado a continuación: 


\begin{tabular}{|l|l|}
\hline Artículo & Descripción \\
\hline Palabras-clave & Conforme a la investigación hecha anteriormente y mostradas arriba. \\
\hline Beneficios & $\begin{array}{l}\text { Se debe también mostrar al consumidor cuales son los beneficios que se } \\
\text { les puede ofrecer. }\end{array}$ \\
\hline Simplicidad & Se debe optar por textos cortos y simples. \\
\hline
\end{tabular}

Fuente: Elaboración propia

Si se tiene un sitio web con un excelente contenido, ciertamente se tendrá diferenciales:

- Cuanto más palabras-clave se tenga, más fácilmente será encontrado el sitio web.

- El cliente tendrá en mente el valor añadido del contenido.

- Links de entrada provenientes de otros sítios web para aumentar la visita.

- Si el sitio es útil, se puede hasta hacer parte de los favoritos del usuario.

\subsection{2 - Links patrocinados}

En algunas situaciones, conforme se ha mostrado por el SEM, estar en la primera página de búsqueda resulta un gran resultado económico por ser fácilmente encontrados. En el caso de esta empresa, como se encuentra en la etapa inicial de construcción de la misma, no se usarán links patrocinados en esta etapa.

\subsection{3- Buscadores}

Concentraremos el sitio web usando palabras-clave definidas pues la oportunidad de ser encontrados por los buscadores aumenta considerablemente.

\subsection{4- Optimizando nuestro sitio web teniendo como base el contenido}

Para comenzar es importante mencionar que Google observa el sitio web por medio det la priorización de páginas (PageRank) y para mejorarlo es necesario que se tenga links externos apuntando para el mismo. Para aumentar el PageRank tendremos links para PMI, la Asociación Brasileña de Normas Técnicas (ABNT), y empresas que actúan en el segmento de proyectos y eso será bueno para mejorar el posicionamiento del sitio web y su clasificación. 


\subsection{5- Criterios de optimización}

Son 2 los criterios a ser considerados:

\begin{tabular}{|l|l|}
\hline Criterio & Descripción \\
\hline Internos & $\begin{array}{l}\text { Son controlados por el dueño del sitio web y el área de marketing pues se } \\
\text { pueden manipular. }\end{array}$ \\
\hline Externos & No son controlados por el dueño del sitio web. \\
\hline
\end{tabular}

Fuente: Elaboración propia

Se hicieron algunas investigaciones y se han detectado los principales criterios que Google utiliza para el análisis de un sitio $w_{e} b^{13}$ :

* Uso de palabras-clave en el título de la página.

* Texto de anclaje en los links de entrada, considerando que texto de anclaje son los links que contienen palabras-clave.

* Autoridad global de los links del sitio y Edad del dominio.

* Popularidad de los links de las estructuras internas de links del sitio web.

* Relevancia del tema de los links de entrada.

* Popularidad de los links del sitio web en la comunidad.

* Popularidad global de los links de los sitios web que se relacionan.

Se hizo una búsqueda su internet y se detectaron más detalles sobre cada artículo mencionado más arriba.

\begin{tabular}{|l|l|}
\hline Artículo & Descripción \\
\hline $\begin{array}{l}\text { Título de la } \\
\text { página }\end{array}$ & $\begin{array}{l}\text { Necesita ser relevante, que tenga entre } 60 \text { y } 70 \text { caracteres } \\
\text { y obviamente, que sea relacionado al negocio de esta empresa. }\end{array}$ \\
\hline Tags & $\begin{array}{l}\text { Es el título del texto que está dentro de la página. La misma lógica } \\
\text { aplicada para el título de la página será también aplicada para los Tags }\end{array}$ \\
\hline
\end{tabular}

Fuente: Elaboracion propia baseada en Vaz, Conrad Adolpho. (2011) Os 8 Ps do marketing digital: o seu guia estratégico de marketing digital, São Paulo: Novatec, pag 477 a 526

${ }^{13}$ Enge, Eric. (2010) Arte do SEO. São Paulo: Novatec No se encuentra enumerado en La bilbiiografia 
continuación de la tabla en la página anterior:

\begin{tabular}{|c|c|}
\hline Artículo & Descripción \\
\hline Meta Tags & $\begin{array}{l}\text { Está en el encabezamiento del código de la página del sitio web. Dos } \\
\text { etiquetas importantes son la Meta Tags Description donde se debe hacer } \\
\text { una descripción relevante de la página en hasta } 160 \text { caracteres y Meta } \\
\text { Tag keywords con un máximo de } 5 \text { palabras. Se usará la misma lógica } \\
\text { de los artículos anteriores. }\end{array}$ \\
\hline Contenido & $\begin{array}{l}\text { Es el más importante punto de atención pues está en base al contenido } \\
\text { de Google el cual hará esta clasificación (uso de palabras-clave) }\end{array}$ \\
\hline $\begin{array}{l}\text { Palabra-clave en } \\
\text { URL }\end{array}$ & $\begin{array}{l}\text { La URL deberá ser amigable. En este caso se usará una URL apuntando } \\
\text { al dueño de la empresa. Así, se usará la URL: www.angelobraga.com.br }\end{array}$ \\
\hline Imágenes & $\begin{array}{l}\text { Mejoran la comprensión del texto y se aprovechará el nombre de la } \\
\text { imagen para insertar una TAG asociada que seguirá las mismas reglas } \\
\text { definida para las TAGS explicadas arriba. }\end{array}$ \\
\hline Links internos & $\begin{array}{l}\text { Se tiene varios links internos indicando a Google las palabras-clave y sus } \\
\text { referencias internas en el sitio web. }\end{array}$ \\
\hline Edad del dominio & $\begin{array}{l}\text { Se opta por usar un dominio nuevo (angelobraga.com.br) aún sabiendo } \\
\text { que se podrá sufrir el riesgo de no ser encontrados. Pero se confía en el } \\
\text { contenido que se presentará como diferencial. }\end{array}$ \\
\hline $\begin{array}{l}\text { Velocidad de } \\
\text { carga }\end{array}$ & $\begin{array}{l}\text { Sin duda, cuanto más demora la página para ser cargada mayor será la } \\
\text { renuncia de accesos. Así, se trabajará para que las páginas sean } \\
\text { cargadas rápidamente. }\end{array}$ \\
\hline Links de entrada & $\begin{array}{l}\text { Para tener muchos links de entrada se está apostando al contenido } \\
\text { generado despertando así el interés de otros sitios web. La meta es } \\
\text { tornarse referencia en el medio. }\end{array}$ \\
\hline Creación de links & $\begin{array}{l}\text { Como ya se dijo anteriormente, la mejor forma de crear links y ser } \\
\text { referenciados como links de entrada es tener un excelente contenido. }\end{array}$ \\
\hline
\end{tabular}

Fuente: Elaboracion propia baseada en Vaz, Conrad Adolpho. (2011) Os 8 Ps do marketing digital: o seu guia estratégico de marketing digital, São Paulo: Novatec, pag 477 a 526 


\subsection{6- Contenido de colaboración}

Se cuenta con contenido colaborativo cuando el usuario o visitante genera tal contenido. Se creará una página donde los usuarios puedan hacer su testimonio sobre los cursos y consultoría que obtuvieron de empresa.

\subsection{7- Elementos persuasivos}

\begin{tabular}{|l|l|}
\hline Elemento & Descripción \\
\hline Números & $\begin{array}{l}\text { Se presentará siempre que sea posible, números demostrando la } \\
\text { eficiencia }\end{array}$ \\
\hline Autoridad & $\begin{array}{l}\text { Se usará el conocimiento de un profesor de FGV (Fundação Getúlio } \\
\text { Vargas) así como su experiencia. }\end{array}$ \\
\hline Prueba Social & $\begin{array}{l}\text { Se indicarán las mejores prácticas y tendencias que todos están siguiendo } \\
\text { en el gerenciamiento de proyectos. }\end{array}$ \\
\hline Reciprocidad & $\begin{array}{l}\text { Se ofrecerán descargas gratuitas de información y también algunos mini } \\
\text { cursos gratis. }\end{array}$ \\
\hline Participación & $\begin{array}{l}\text { Para que el usuario haga las descargas deberá dejar su correo } \\
\text { electrónico. }\end{array}$ \\
\hline Escasez & $\begin{array}{l}\text { Se harán promociones con tiempo limitado para compras colectivas de } \\
\text { capacitaciones. }\end{array}$ \\
\hline Call to action & $\begin{array}{l}\text { En este sitio web el usuario podrá consultar capacitaciones (contenido y } \\
\text { precios) y servicios de consultoría. }\end{array}$ \\
\hline
\end{tabular}

Fuente: Elaboración propia

\subsection{8 - Contenido off-site}

Además de este sitio web se usarán otros excelentes sitios web para publicar el contenido producido off-site. Ellos son:

\begin{tabular}{|l|l|}
\hline Sitio Web & Finalidad \\
\hline Youtube, Flickr, Slideshare & Vídeos, fotos y documentos \\
\hline Scribd & Documentos \\
\hline Picasa, DocSotc, MetaCafe, & Fotos \\
\hline PodBean, BlogTalkRadio, Podomatic & Podcasts \\
\hline
\end{tabular}

Fuente: Elaboracionn propia 
Como los sitios web mencionados están bien ranqueados, Google les da prioridad para hacer una investigación. Cuanto más contenido digital se publique, más conocida será la marca.

\subsection{9- Blogs}

Los blogs representan la verdadera forma de expresión de todos los miembros de la Web. Así el blog será una herramienta importante para expresar opinión y consecuentemente volverá más conocidos y respetados por los clientes.

\section{5- Promoción}

Se debe buscar una promoción viral, es decir, una promoción masiva que llegue a todos los interesados. Para eso se debe estar atentos a los siguientes puntos:

- Se necesita dar motivos para que el cliente vuelva al sitio web.

- La promoción debe generar valor añadido, es decir, ser relevante para el público.

- La promoción necesita tener un público - objetivo específico

- Si la promoción es buena, estimulará el boca a boca y así ganará un efecto de propagación como compartir en el Facebook, retweets, etc.

Formas de hacer la promoción a través de Internet:

\begin{tabular}{|l|l|}
\hline Tipo & Descripción \\
patrocinados & $\begin{array}{l}\text { Es una acción que depende de que el usuario busque el link. En } \\
\text { este negocio no se usará links patrocinados. }\end{array}$ \\
\hline $\begin{array}{l}\text { Campañas de redes } \\
\text { sociales }\end{array}$ & $\begin{array}{l}\text { Hacen parte de la divulgación de la empresa y crean un contenido } \\
\text { apuntando al Hotsite. Se usarán -muchas campañas en las redes } \\
\text { sociales }\end{array}$ \\
\hline Programas de afiliación & $\begin{array}{l}\text { Es un programa donde se podrá mantener el cliente a través de la } \\
\text { afiliación. En el negocio se usarán programas de afiliación para los } \\
\text { alumnos que hagan las capacitaciones. }\end{array}$ \\
\hline Campañas de email- & $\begin{array}{l}\text { Se debe captar una lista de e-mail y después generar la campaña } \\
\text { para estos e-mails. En esta empresa se creará un email list. A partir } \\
\text { de ahí se harán las acciones de email marketing para esta lista. }\end{array}$ \\
\hline Redacción de artículos & \begin{tabular}{l} 
Se puede divulgar la marca escribiendo artículos. \\
\hline
\end{tabular} \\
\hline
\end{tabular}




\begin{tabular}{|l|l|}
\hline $\begin{array}{l}\text { Comunicados para la } \\
\text { prensa }\end{array}$ & $\begin{array}{l}\text { Tener lanzamientos para que la prensa ayude a divulgar las } \\
\text { novedades y la marca. Se crearán lanzamientos en el sitio web. }\end{array}$ \\
\hline
\end{tabular}

Fuente: Elaboración propia

\subsection{1- Campañas en medios de comunicación social}

Se pueden usar varias herramientas del Twitter para activar una campaña: a través del TwtQpon (http://twtapon.com) se pueden crear cupones de descuentos vía Twitter o TwtVite (http://twtvite.com) para invitar a los usuarios a participar de eventos y verificar también las respuestas dadas por los usuarios.

Sin duda las mejores formas de desarrollar diálogos con los usuarios es a través del blog y del facebook.

Se creará una página en el Facebook para tener amigos, seguidores y verificar cuantos disfrutan de nuestra marca. Esto también se aplicará a las campañas. Se tiene que entender cuál es el contenido que se debe preparar pues en algunos medios de comunicación se necesita de la colaboración de las personas para crear algo, para generar contenido y consumir contenido. Ellos son:

* Redes sociales: Facebook, Myspace, Linkedln

* Sitios web de mensajes cortos: Twitter

* Sitios de contenido colaborativo: Flickr para fotos, Youtube para vídeos.

* Medios de comunicación social con base en imágenes y vídeos: Zoomr, Slide, MediaConvert, Photobucket, Grafitti, Vuvox, Soundation. ${ }^{15}$

Un recurso humano de la empresa será responsable de realizar el trabajo descrito anteriormente. Todas las ubicaciones antes mencionadas son parte de las redes sociales e Internet, y es donde los clientes potenciales están. Por lo tanto, la mezcla de estos medios promoverá nuestros productos y servicios.

\footnotetext{
Ts www.zoomr.com, www.slides.com, media-convert.com, www.photobucket.com, http://windows.microsoft.com/ptbr/windows-live/movie-maker, www.vuvox.com e www.soundation.com/studio
} 


\subsection{2- E-mail marketing}

Es una de las mejores herramientas de marketing directo. Cuando se esté en el momento fundacional de una empresa, como es este caso, el primer e-mail marketing que hagamos tiene como objetivo iniciar la relación con el cliente. Por lo tanto, se presenta a la empresa, su visión, sus productos y cómo generar valor añadido para los potenciales clientes.

El rendimiento previsto de la publicidad directa a través de e-mail es del $1 \%$ al $5 \%$, esto en un caso excepcional. Para obtener este índice hay que entender que no se debe hacer spam, y por lo tanto, la compra de listas de correo electrónico no es la mejor estrategia.

Se generará una lista propia de correos electrónicos basados en nuestros correos electrónicos entrantes, contactos del Twitter, Facebook, Linkedin y los clientes que se registren en nuestro sitio web.

Para los clientes que se registren en el sitio y que tengan interés para acceder a la zona restringida de descargas, deberán dejar su correo electrónico registrado. El primer correo electrónico enviado al cliente es muy importante y debe tener contenido relevante. Obviamente hay que respetar el deseo de los consumidores y añadir la famosa frase "si no desea recibir nuestros mensajes de correo electrónico, haga clic aquí para cancelar la suscripción."

\section{6- Propagación}

La propagación trata de comunicación hecha de forma viral que se produce de consumidor a consumidor. Depende de la voluntad de los consumidores para transmitir el mensaje.

El primero en recibirlo, lo hace por su consentimiento, por ejemplo a través de un correo electrónico. A partir de ahí, si él percibe el valor y considera importante compartir con sus amigos, lo hará de forma espontánea.

Hay una regla $90 / 9 / 1^{16}$ donde sólo el $1 \%$ crea la comunicación para el mercado, el $9 \%$ sólo pasa la información para adelante y sólo el $90 \%$ apenas se quedan con la información y la consumen sin transmitirla a nadie.

\footnotetext{
${ }^{16}$ Nielsen, Jakob. (2006) Estudo Publicado, http://www.nngroup.com/articles/participation-inequality/
} 


\subsection{1- Facebook}

Se creará una página en Facebook ya que es una buena forma de comunicarse con los clientes. Existirá una página para la marca de la empresa, y se mantendrá la página personal del representante de la empresa. Esto porque la página de perfil tiene un límite de 5 mil amigos en cuanto que la página de fans no tiene ningún límite. No se pretende limitar a la empresa a 5 mil potenciales clientes.

La página de fans puede personalizarse a través del lenguaje propio de Facebook llamada Facebook Markup Language (FBML), o podemos usar el software Pagemodo ${ }^{17}$ para este cometido. Se debe también conocer los conceptos de EdgeRank ${ }^{18}$ que se describe a continuación. Se basa en 3 pilares ${ }^{19}$.

$\checkmark$ Afinidad: En cuanto se integran ambas páginas (visitando el perfil/página, dejando mensajes en el muro, visualizando fotos, disfrutando, comentando o compartiendo), el Facebook genera un grado de afinidad que tiene gran peso

$\checkmark$ Relevancia: Cuando una nueva publicación sea hecha, los que tienen más afinidad la visualizan inmediatamente. De acuerdo con la receptividad de esas personas (o cuanto hacen clic, disfrutan, comentan o comparten) el mensaje va siendo exhibido a más y más personas. De acuerdo con testeos, las fotos y vídeos son más relevantes que los textos y links, por ejemplo.

$\checkmark$ Tiempo: Los mensajes más recientes poseen prioridad y son exhibidas antes que los mensajes más antiguos.

\section{Como mejorar los resultados y el EdgeRank}

Algunas noticias recientes indican que "apenas $12 \%$ de las personas que disfrutaron una página visualizan las actualizaciones de status de esa página” ${ }^{19}$. Pocas empresas entienden eso y hacen poco para superar los desafíos del EdgeRank y conseguir mejores resultados. A continuación algunas consideraciones que pueden hacer la diferencia:

\footnotetext{
${ }^{17}$ www.pagemodo.com

${ }^{18}$ un algoritmo del Facebook que hace que ni todas las publicaciones aparecen en las páginas. http://resdigitais.wpengine.netdna-cdn.com/materiais-educativos/files/2012/08/Novo-eBook-Marketing-no-Facebook.pdf

${ }^{19} \mathrm{http}$ ///resultadosdigitais.com.br/blog/como-o-edgerank-do-facebook-funciona-e-por-que-isso-e-importante-para-suaempresa/

${ }^{19} \mathrm{McGee}$, Matt (Aug 16, 2013). "EdqeRank Is Dead: Facebook's News Feed Alqorithm Now Has Close To 100K Weight Factors". http://marketingland.com/edgerank-is-dead-facebooks-news-feed-algorithm-now-has-close-to-100k-weight-factors-55908
} 


\begin{tabular}{|c|c|}
\hline Acción & Descripción \\
\hline $\begin{array}{l}\text { Usar imágenes } \\
\text { y vídeos }\end{array}$ & $\begin{array}{l}\text { Las imágenes y vídeos no sólo poseen una relevancia mayor, en función de los } \\
\text { colores y del tamaño que ocupan en el feed de noticias, sino que acaban } \\
\text { llamando mucho más la atención del usuario. }\end{array}$ \\
\hline $\begin{array}{l}\text { Hacer } \\
\text { preguntas }\end{array}$ & $\begin{array}{l}\text { Las preguntas tienen por naturaleza la sensibilidad, la interacción, exactamente } \\
\text { lo que necesitamos para aumentar la relevancia de la publicación. }\end{array}$ \\
\hline $\begin{array}{l}\text { Escoger buenos } \\
\text { horarios para } \\
\text { publicar }\end{array}$ & $\begin{array}{l}\text { El horario de la publicación hace la diferencia en los resultados. Entender los } \\
\text { hábitos del público y descubrir cuáles son los horarios pico, puede tener un } \\
\text { impacto significativo en las publicaciones. Domingo por la noche, por ejemplo, } \\
\text { es buen momento para actualizaciones en Facebook. }\end{array}$ \\
\hline $\begin{array}{lr}\text { Filtrar bien } & \text { el } \\
\text { contenido } & y \\
\text { determinar } & \text { una } \\
\text { buena } & \\
\text { frecuencia } & \end{array}$ & $\begin{array}{l}\text { Si una empresa tiene poco criterio al publicar contenidos, el resultado será que } \\
\text { mucha gente ignorará o, peor aún, ocultará sus publicaciones. Eso es pésimo } \\
\text { para la relevancia y afinidad. Hay que intentar publicar por lo menos una vez al } \\
\text { día, pero ser riguroso: solamente contenido de calidad. }\end{array}$ \\
\hline $\begin{array}{l}\text { Pedir para obrar } \\
\text { recíprocamente }\end{array}$ & $\begin{array}{l}\text { Al hacer una actualización, puede ser interesante añadir un pedido de compartir } \\
\text { o comentar. Eso puede funcionar como un incentivo extra para que las personas } \\
\text { realmente hagan esas acciones. }\end{array}$ \\
\hline $\begin{array}{l}\text { Usar } \\
\text { promover }\end{array}$ & $\begin{array}{l}\text { Facebook lanzó hace poco tiempo el recurso "promueva", que exhibe una } \\
\text { actualización para personas que no la verían de forma (gratuita).Con } \\
\text { esta herramienta, que es paga, es posible expandir el alcance del mensaje. }\end{array}$ \\
\hline \begin{tabular}{ll|} 
Medir en el \\
Insights
\end{tabular} & $\begin{array}{l}\text { Facebook ofrece una óptima opción de análisis, el Insigths, que muestra } \\
\text { cuantas veces cada publicación fue visualizada, si se entró y tuvo interacciones. }\end{array}$ \\
\hline
\end{tabular}

Fuente: Elaboración propia

\subsection{2- Twitter}

Se trata de una herramienta de marketing directo. A través de él podemos estar en contacto directo con nuestro público. Para ello contamos con un excelente layout del perfil de la empresa con la cual nuestra marca se identifica desde el principio. Siempre hablaremos de nuestra especialidad que es la consultoría en gestión de proyectos y siempre que hablemos del tema direccionaremos con links a nuestro sitio web, nuestro blog, Youtube, Slideshare, etc. Para dar continuidad, podemos seguir los siguientes pasos: 


\begin{tabular}{|l|l|}
\hline Etapa & Descripción \\
\hline Inicial & Hacer una investigación por Tags o palabras-clave en Twitter \\
\hline Etapa 1 & $\begin{array}{l}\text { Podemos seguir todos los twitteros que poseen esa palabra-clave Para eso } \\
\text { usaremos el TwitterSearch y el TwitterTag }\end{array}$ \\
\hline Etapa 2 & $\begin{array}{l}\text { Podemos visualizar una nube de tags buscando por los símbolos \# que } \\
\text { indica el tema en tweet, es decir, sea una hashtag. }\end{array}$ \\
\hline Etapa 3 & $\begin{array}{l}\text { Podemos también buscar a los usuarios a través del símbolo @ y dirigirle } \\
\text { un mensaje. }\end{array}$ \\
\hline
\end{tabular}

Fuente: Elaboracion propia baseada en Vaz, Conrad Adolpho. (2011) Os 8 Ps do marketing digital: o seu guia estratégico de marketing digital, São Paulo: Novatec, pag 706 a 720

A través de Twitter, también sabremos cómo va nuestra campaña. A través del acortador http://bit.ly/ tenemos los resultados del número de retweets, comentarios, la cantidad de clics en el link. Con esto buscamos entender el comportamiento de nuestro público.

Nuestra estrategia es usar la herramienta para crear una comunidad con nuestros clientes y futuros clientes, proveedores y empleados de nuestra empresa. A partir de ahí produciremos nuestro contenido. También seguiremos el twitter de grandes empresas de nuestro sector para saber lo qué está pasando en el mercado.

Por último, analizaremos como está nuestro sitio web con las siguientes herramientas:

\begin{tabular}{|l|l|}
\hline Herramienta & Uso \\
\hline Backtweets $^{20}$ & Encontrar links que queremos investigar. \\
\hline Check Retweet $^{20}$ & Comprobar cuantos retweets tuvimos. \\
\hline${\text { Twitter } \text { Count }^{20}}^{20}$ & Muestra el histórico de seguidores. \\
\hline Tweetstats $^{20}$ & Estatísticas del número de tweets \\
\hline
\end{tabular}

Fuente: Elaboracion propia baseada en Vaz, Conrad Adolpho. (2011) Os 8 Ps do marketing digital: o seu guia estratégico de marketing digital, São Paulo: Novatec, pag 706 a 720

\subsection{3- LinkedIn}

Linkedin es una fuente de contactos por tratarse de una red centrada en la carrera y vida profesional de las personas. Como lidiamos con capacitaciones destinadas a mejorar la carrera profesional, sin duda podremos utilizar Linkedin para promocionar nuestros productos.

\footnotetext{
${ }^{20}$ backtweets.com, www.checkretweet.com, twittercounter.com e tweetstats.com
} 
Aún más, tiene integración con Twitter y Facebook. El perfil de Linkedin es la mejor opción para encontrar profesionales, ya sean clientes o proveedores, pues tenemos la posibilidad de filtrarlos por especialidad. También podemos utilizar algunas de las funciones de Linkedin. Podemos encontrar personas que quieren ponerse en contacto. También hay herramientas de búsqueda de personas que pueden usar filtros para encontrar a nuestro público. Por último, los grupos de discusión son una gran fuente para encontrar personas de ideas afines. Dado que los proyectos de nuestra área pueden ser parte del grupo de proyectos para facilitar nuestra penetración.

\subsection{4- Redes sociales de Nicho}

Vamos a tratar de entrar en algunas redes que son muy específicas para la gestión de proyectos. Como ejemplo podemos mencionar la Revista Mundo $\mathrm{PM}^{21}$, que es una revista bimensual y una referencia en Brasil y en Revista Pequeñas y Medianas Empresas ${ }^{22}$, con varios artículos sobre servicios de consultoría en gestión de proyectos. Esta última es nuestro objetivo.

\subsection{5- Youtube}

No podemos dejar de considerar a Youtube, ya que es el segundo mayor motor de búsqueda en el mundo, sólo detrás de Google. Crearemos nuestra página de YouTube donde presentaremos nuestros nuevos productos al público. Unir marketing de guerrilla a videos en Youtube puede funcionar. Un buen vídeo puede propagarse fácilmente a través de la relación de persona a persona.

\subsection{6- Interacción basada en la cooperación}

Se trata de la compra colectiva. Sin duda utilizaremos este tipo de promoción. Crearemos ofertas en sitios de compras colectivas ${ }^{23}$. La promoción en esta modalidad será utilizada solamente para capacitaciones donde nuestra idea es construir clases de capacitación con un número mínimo de alumnos.

\footnotetext{
${ }^{21}$ www.mundopm.com.br

${ }^{22} \mathrm{http}: / / \mathrm{g} 1 . \mathrm{globo} . \mathrm{com} / \mathrm{economia} / \mathrm{pme} / \mathrm{index} . \mathrm{htm}$

$1^{23}$ www.peixeurbano.com.br, www.groupon.com.br
} 


\section{7- Personalización}

A través de Internet se puede hacer marketing uno a uno de forma personalizada, es decir, podemos personalizar la comunicación con cada uno de nuestros clientes. Cuanto más se personaliza la relación con nuestros clientes y mercado, más aumentamos nuestro capital social.

Para controlar esta personalización y la relación, se recomienda tener un instrumento de Customer Relationship Management (CRM). Como nuestra empresa se encuentra al comienzo de las operaciones optaremos por una herramienta open source llamada Sugar $\mathrm{CRM}^{24}$ en conjunto con Insightly ${ }^{25}$ que es un sistema online y, finalmente, el Highrise ${ }^{26}$ que es una programación de los perfiles profesionales.

Además del CRM, la personalización también pasa por el contacto directo con el consumidor a través del chat, teléfono o cualquier otro medio. Nuestra empresa tendrá un chat en línea y un teléfono para que el cliente entre en contacto. Otro punto importante es que la persona que entre en el chat informará su correo electrónico para ser puesto en nuestra lista de distribución de publicidades.

\subsection{1- Personalización a través de e-mail marketing}

Como tenemos nuestra propia lista, conoceremos bien el perfil de nuestros clientes y por lo tanto podemos enviar comunicaciones dirigidas construyendo así una relación. Al segmentar estaremos creando más valor para nuestros clientes, que seguramente generará una reciprocidad.

Nuestra idea siempre fue generar correos electrónicos personalizados. Para ello se utiliza una herramienta llamada Constant Contact que nos ayudará a elaborar e-mails con segmentación.

\footnotetext{
${ }^{23}$ www.peixeurbano.com.br, www.groupon.com.br

${ }^{24} \mathrm{http}$ ://www.sugarforge.org/content/open-source/

${ }^{25} \mathrm{http}: / / \mathrm{www}$.insightly.com

${ }^{26} \mathrm{https}$ //highrisehq.com/
} 


\section{8- Precisión}

La precisión está directamente relacionada a la forma como mediremos los resultados que estamos obteniendo con nuestras acciones de marketing digital.

Para medir la precisión usaremos una herramienta que describiremos a continuación: será Gooble Web Site Optimizer que Mide el desempeño de versiones diferentes de sitios web, botones, etc.

No vamos a utilizar las otras herramientas (Sitespect, Vertster, etc), ya que son pagas y como estamos en el comienzo de nuestro proyecto no queremos costos adicionales. Para que nuestra medición sea posible es necesario definir las métricas que seguiremos. Ellas son:

\begin{tabular}{|l|l|}
\hline Artículo & Descripción \\
\hline Lo que usaremos para medir & Google Analytics. \\
\hline Período del testeo. & 30 días. \\
\hline Donde veremos los resultados. & Directamente en Google Analytics. \\
\hline Meta principal: Contactos diarios. & $\begin{array}{l}\text { Deseamos tener en nuestro sitio web 10 contactos } \\
\text { diarios. }\end{array}$ \\
\hline Análisis estadístico. & Media de 10 usuarios por día visitando el sitio web \\
\hline Meta principal: email marketing. & Deseamos 5\% de tasa de.retorno \\
\hline $\begin{array}{l}\text { Meta principal: recibir email con pedidos de } \\
\text { información. }\end{array}$ & Deseamos 1 e-mail por día con tales pedidos. \\
\hline
\end{tabular}

Fuente: Elaboración propia

Planteamos como meta principal el número de accesos a la página web, deseamos evolucionar de 5 visitas en el primer mes creciendo hasta 100 visitas en el $12^{\circ}$ mes. Queremos mostrar el porcentaje de abandonos del sitio. Mediremos quien se quedó en nuestro sitio web, por menos de 10 segundos. Así pues, nuestro deseo es que esta tasa se reduzca aún más. El porcentaje deseado es que la tasa de abandono sea del $10 \%$.

\subsection{1- Monitoreo de nuestra palabra-clave}

Uno de los puntos en los cuales debemos prestar mucha atención es en el ranking de nuestras palabras clave, es decir, si ella no está en una buena posición en el ranking de 
palabras. Como se mencionó anteriormente buscaremos herramientas gratuitas para hacer este trabajo. Utilizaremos dos herramientas:

1. Rank Tracker. veremos la clasificación en Google de cada palabra que deseamos usar.

2. Herramientas para webmaster de Google: evaluaremos la tasa de conversión en tipeos en cada una de las palabras-clave.

Nuestra intención es tener un CTR (número de clics / número de impresiones del sitio web en la pantalla) alto. Si tenemos un CTR bajo puede indicar que nuestra posición en las búsquedas es malo o que los resultados mostrados en la búsqueda no está atrayendo a los consumidores.

\subsection{2- Página de entrada}

En nuestro caso, sin duda será la página principal del sitio web que será una página donde el cliente podrá ver todas las opciones disponibles en el sitio. La premisa básica es que sea una página cargada para no cansar al consumidor y no produzca desinterés debido a su complejidad.

\subsection{3- Links externos}

Utilizaremos la herramienta Webmaster de Google para ver la cantidad de sitios que hacen referencia a la nuestra. Nuestra intención es que este número crezca y se convierta en un referente para las empresas. Esto es importante porque, como se mencionó anteriormente, el pagerank (es un algoritmo utilizado por la herramienta de búsqueda de Google para posicionar sitios web entre los resultados de sus búsquedas) de Google es influenciado por el número de enlaces externos del sitio web.

\subsection{4- Como hacer las mediciones}

Usaremos, como ya se ha mencionado, el Google Analytics que es un software gratuito y que nos dará las informaciones del número de accesos al sitio web, en donde los consumidores están haciendo más clic, y donde no lo hacen, etc. Esto nos ayudará a mejorar nuestro sitio web.

\subsection{5- Mensuración/medición en redes sociales}

Utilizaremos los siguientes parámetros: 


\begin{tabular}{|l|l|}
\hline Objetivo & Métrica \\
\hline Cuantas personas se adhieren a mi marca. & Crecimiento de 1 seguidor/día \\
Número de retweets, comentarios en Facebook, blog, etc. & 5 comentarios por día \\
Número de ventas que generamos a partir de las redes & 1 por semestre \\
sociales. & \\
\hline
\end{tabular}

Fuente: Elaboración propia

Las herramientas que usaremos para eso serán todas las herramientas gratuitas del Facebook, Twitter y Blogs.

\subsection{6- Mensuración/medición de e-mail marketing}

Para medir la efectividad de una campaña de email marketing debemos crear algunos parámetros que se muestran a continuación. En este caso mostramos abajo los parámetros y las posibles causas de un bajo número de respuestas:

\begin{tabular}{|c|c|c|}
\hline Artículo & Parámetro & Explicación / causa \\
\hline Emails enviados & $\begin{array}{l}\text { Deseamos alcanzar } 1.000 \\
\text { direcciones válidas. }\end{array}$ & Indica nuestra penetración en el mercado. \\
\hline Emails liberados & $\begin{array}{l}\text { Deseamos alcanzar } 98 \% \\
\text { de e-mails enviados. }\end{array}$ & $\begin{array}{l}\text { Indica la cantidad de nuestros datos. } \\
\text { Cuanto mayor la tasa mejor es La cantidad. }\end{array}$ \\
\hline $\begin{array}{l}\text { Emails borrados } \\
\text { antes de apertura }\end{array}$ & Tasa máxima de $5 \%$ & $\begin{array}{l}\text { Cuanto mayor es la tasa mayor indicio } \\
\text { tenemos de que nuestro título no fue } \\
\text { atractivo. }\end{array}$ \\
\hline $\begin{array}{l}\text { Emails que fueron } \\
\text { abiertos }\end{array}$ & Tasa esperada de $90 \%$ & $\begin{array}{l}\text { Muestra cuan atractivo es el título. Cuanto } \\
\text { menor el \% indica que el título es pésimo. }\end{array}$ \\
\hline $\begin{array}{l}\text { Emails que fueron } \\
\text { cliqueados }\end{array}$ & Tasa esperada de $80 \%$ & $\begin{array}{l}\text { Cuanto mayor es la tasa significa que } \\
\text { alcanzamos el deseo del cliente. Si la tasa } \\
\text { es menor significa que el contenido del } \\
\text { email está malo y que necesitamos } \\
\text { mejorarlo. }\end{array}$ \\
\hline $\begin{array}{l}\text { Emails que pidieron } \\
\text { la cancelación del } \\
\text { registro }\end{array}$ & Tasa esperada de $1 \%$ & $\begin{array}{l}\text { Cuanto mayor sea esa tasa indica que no } \\
\text { estamos consiguiendo alcanzar al cliente. }\end{array}$ \\
\hline
\end{tabular}

Fuente: Elaboración propia 
Para la realización de nuestra campaña de email utilizaremos una herramienta con esta finalidad. Como tenemos un presupuesto inicial pequeño no haremos campañas semanales.

\section{9- Consideraciones importantes para nuestro proyecto}

Entendemos que con la parametrización y las reglas mencionadas anteriormente, lograremos nuestros objetivos ya que las normas y decisiones son la base para la próxima sesión, que es la creación de la empresa y el uso de herramientas de marketing digital para apalancar los negocios de esta empresa. Por lo tanto, vamos a basarnos en $100 \%$ en las herramientas de marketing digital para apalancar nuestra empresa de forma rápida, eficiente y fiable. 


\section{4 - Proyecto para la creación de una empresa que usará solamente marketing digital para su divulgación}

Después de lo expuesto en los apartados anteriores desarrollaremos nuestro proyecto de marketing digital. Para ello utilizaremos el concepto de Proyecto que es la creación de un producto o servicio único que debe ser ejecutado, controlado y con fecha certera de inicio y finalización. En nuestro caso el producto será la creación de la empresa que presta servicios de consultoría y capacitación en gestión de proyectos, cuya divulgación se basa en $100 \%$ en el marketing digital.

Como se ha mostrado anteriormente el proyecto entregará el subproducto:

\begin{tabular}{|l|l|}
\hline Sub-Producto & Descripción \\
\hline Sitio web & $\begin{array}{l}\text { Se trata de la principal herramienta de la empresa y será a partir del } \\
\text { mismo que los clientes se familiarizarán con lo que la empresa propone. }\end{array}$ \\
\hline
\end{tabular}

Fuente: Elaboración propia

Y se usarán las siguientes herramientas de marketing digital:

\begin{tabular}{|l|l|}
\hline Sub-Producto & Descripción \\
\hline Blog & Escribiremos un blog para aumentar nuestra penetración. \\
\hline Email marketing & Será la forma de mostrar directamente al cliente que existimos. \\
\hline Podcasts & Otra oferta de contenido gratis para los clientes. \\
\hline Videocasts & Lo mismo que el Podcast. \\
\hline Redes Sociales & $\begin{array}{l}\text { Estaremos presentes también en Facebook, Linkdin y Twitter -> aumentar } \\
\text { la gestión de información. }\end{array}$ \\
\hline RSS & Otra forma de propagación de nuestra empresa. \\
\hline $\begin{array}{l}\text { Mecanismos de } \\
\text { búsqueda (SEM) }\end{array}$ & $\begin{array}{l}\text { Mecanismos con palabras-clave para mejorar nuestra gestión de } \\
\text { información. }\end{array}$ \\
\hline
\end{tabular}

Fuente: Elaboración propia

¿Por qué optamos por usar estas herramientas de marketing digital para apalancar nuestro proyecto? La explicación está en la figura de abajo que hace la correlación de las herramientas de marketing digital con las herramientas de marketing tradicional. 


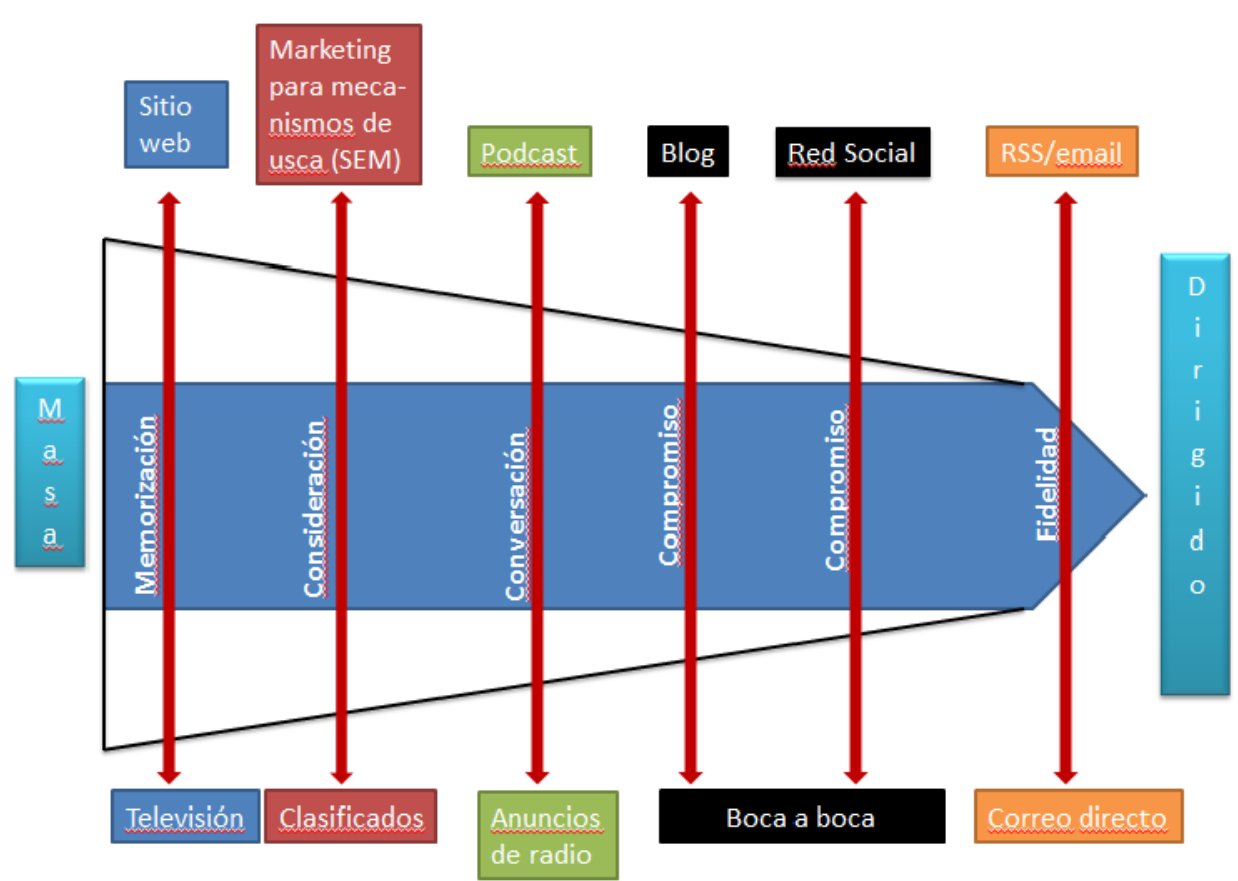

Fuente: Reed, Jon. (2012) Marketing Online - Como usar sites, blogs, redes sociais e muito mais. São Paulo, Editora Lafonte, página 19

¿Y por qué se optó por utilizar Marketing Digital? La respuesta se basa en el principio de que el marketing digital es mucho más rentable /eficiente que el marketing tradicional, nuestros principales clientes seguramente estarán más tiempo conectados online que viendo las herramientas de marketing tradicionales. Otros motivos para usar el marketing digital son:

- Mostraremos nuestros productos y servicios de forma online direccionado a nuestro sitio web.

- El mercado hoy en día usa mucha información online.

- Las informaciones están explícitas generando así confianza con nuestro cliente.

- Tendremos varios canales de comunicación para iniciar una conversación con nuestro cliente.

- Podemos construir comunidades o hacer parte de las ya existentes.

- Podemos proveer informaciones rápidas y precisas aumentando la satisfacción del cliente.

- Como el cliente está online, nosotros recopilaremos sus datos básicos para la comunicación futura.

- Podemos hacer investigación de mercado online con nuestros propios clientes o futuros clientes. 
Tenemos un costo operacional muy abajo (dominio, mantenimiento del sitio web, solo soporte administrativo) y herramientas sabiamente eficaces para hacer marketing.

Otro punto de atención que debemos tener presente es que utilizaremos un conjunto de herramientas y plataformas en línea. Este sistema incluye el Sitio Web, Facebook, Linkedin, Twitter, blogs, podcasts, videos en línea. Este conjunto de herramientas se llama medios de comunicación social, y para ser encontrados debemos pensar como Google piensa, porque hoy en día la gente piensa según Google. Por lo tanto, para los logros en el mundo de las redes sociales utilizaremos algunos conceptos:

a Como estamos en el inicio de la operación no haremos procesos de ventas agresivas y no enviaremos mensajes no solicitados a nuestros futuros clientes.

- Crearemos una relación siempre abierta, auténtica y transparente pues ella se apoyará en nuestro universo online (nuestro sitio web como referencia).

- Estaremos en diversos puntos de las redes sociales, en diversos sitios web tales como Facebook, Youtube, Linkedln y Twitter, siempre publicando mensajes con alto valor añadido.

- No la usaremos de forma unidireccional, pues queremos abrir espacio para la conversación con nuestros clientes y futuros clientes.

La elección de nuestras herramientas fueron definidas considerando los criterios de las que deseamos usar, herramientas de contenido para generar nuestra propia información, herramientas de distribución para hacer que nuestra información llegue a nuestros clientes, herramientas de escucha para obtener el feedback y descubrir nuevas necesidades de nuestros clientes y del mercado y finalmente herramientas de medición para analizar como está yendo nuestra rendimiento desde el punto de vista de los negocios.

La figura a seguir muestra cómo será el uso de nuestras herramientas de marketing online. 


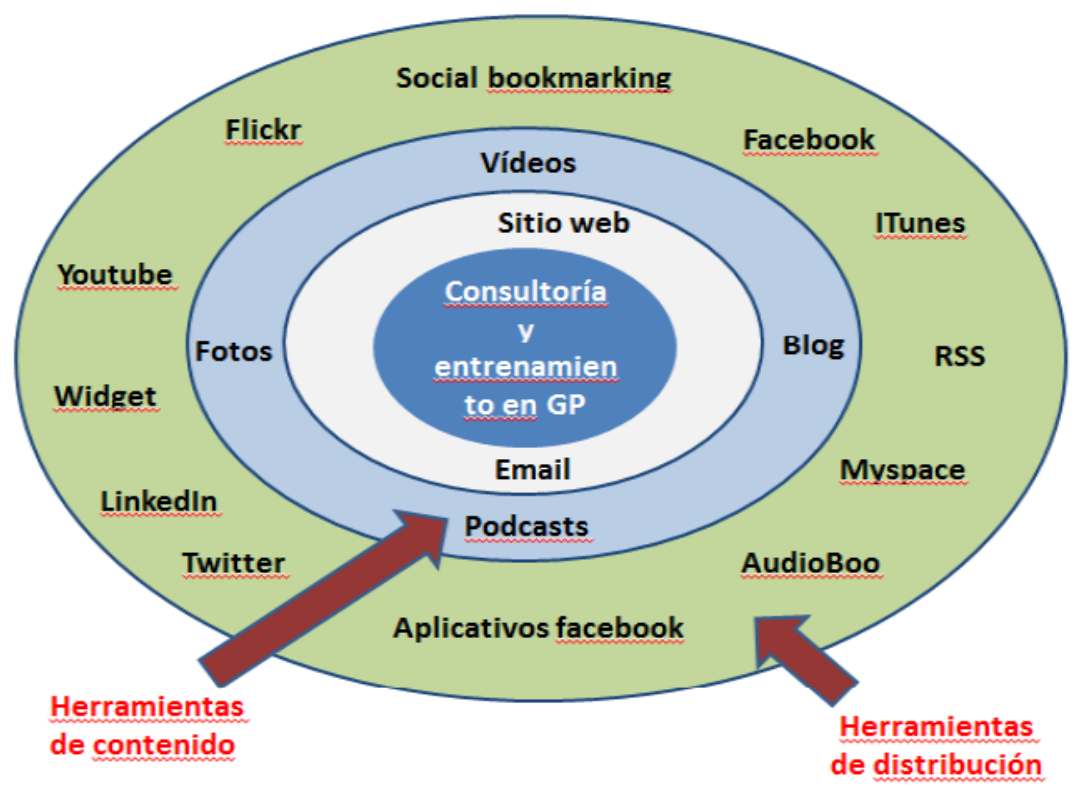

Fuente: Reed, Jon. (2012) Marketing Online - Como usar sites, blogs, redes sociais e muito mais. São Paulo, Editora Lafonte, página 32

Podemos ver en la figura de arriba que tenemos una relación completa de herramientas de contenido y distribución. Sin embargo, no usaremos todas. La tabla abajo muestra las herramientas seleccionadas:

\begin{tabular}{|l|l|l|}
\hline Tipo & Herramientas & Finalidad \\
\hline Contenido & $\begin{array}{l}\text { YouTube } \\
\text { BLOG e Sitio Web Institucional. }\end{array}$ & $\begin{array}{l}\text { Audio y vídeo } \\
\text { Textos y Textos }\end{array}$ \\
\hline Distribución & $\begin{array}{l}\text { Flickr, Facebook, Feed RSS, Twitter, } \\
\text { Youtube, LinkedIn, Widgets, Email, Sitio } \\
\text { institucional. }\end{array}$ & $\begin{array}{l}\text { Hacer con que las } \\
\text { informaciones de nuestros } \\
\text { productos lleguen hasta } \\
\text { nuestros clientes en } \\
\text { potencial. }\end{array}$ \\
\hline Escucha & Las mismas herramientas de distribución & $\begin{array}{l}\text { Recibir feedback del cliente. } \\
\text { Medición }{ }^{29}\end{array}$ \\
& $\begin{array}{l}\text { Twitter Counter } \\
\text { Twitteranalyzer } \\
\text { Twitterstats } \\
\text { Google Analytics } \\
\text { Getclicky }\end{array}$ & $\begin{array}{l}\text { Medir la eficiencia de } \\
\text { nuestras campañas para } \\
\text { evaluar si estamos llegando } \\
\text { a nuestros clientes. }\end{array}$ \\
\hline
\end{tabular}

Fuente: Elaboracion Propia

${ }^{29}$ www.twittercounter.com, www.twitalyzer.com, www.tweetstats.com, www.google.com/analytics; www.getclicky.com 
Para el último artículo, Medición, adoptaremos los siguientes artículos de control:

\begin{tabular}{|l|l|}
\hline Artículo & Descripción / Herramienta \\
\hline $\begin{array}{l}\text { Cantidad de accesos a nuestro } \\
\text { sitio web. }\end{array}$ & $\begin{array}{l}\text { Es muy importante saber cuántas personas están } \\
\text { visualizando nuestra información. Vamos a usar 2 } \\
\text { herramientas: Google Analytic y Clicky Web Analytics. }\end{array}$ \\
\hline $\begin{array}{l}\text { Cantidad de usuarios que entran } \\
\text { nuestras herramientas. }\end{array}$ & $\begin{array}{l}\text { Contaremos los siguientes indicadores: } \\
\text { Cuantos adeptos en Facebook, seguidores en Twitter, } \\
\text { conexiones en Linkedin y cuantos feed RSS }\end{array}$ \\
\hline $\begin{array}{l}\text { Posición de nuestro blog y } \\
\text { Twitter. }\end{array}$ & $\begin{array}{l}\text { Vamos a analizar cómo está el ranking de nuestro blog en el } \\
\text { sitio Technorati } \\
\text { sitio } \text { y cual la posición de nuestro Twitter en el }\end{array}$ \\
\hline $\begin{array}{l}\text { Cual la eficacia de nuestras } \\
\text { promociones. }\end{array}$ & $\begin{array}{l}\text { Vamos a medir cuantas personas atendieron al mensaje de } \\
\text { nuestra promoción. Así veremos la eficacia de la misma. } \\
\text { Crearemos cebos digitales para atraer clientes. }\end{array}$ \\
\hline
\end{tabular}

Fuente: Elaboración propia

\section{1- Primera herramienta: Sitio $W e b$ de la Empresa}

Home: Será la página de presentación del sitio web. Como es la página principal, será una página limpia y contendrá un mensaje indicando los productos y servicios que vendemos. Obviamente va a estar lleno de palabras clave.

Institucional: Será la presentación de la empresa conteniendo misión, visión, valores y principales clientes.

Loqin: Será la página en la que el usuario se registrará para obtener acceso exclusivo al sitio web. También será redirigido para las páginas que él podrá acceder.

El login será compuesto de dos campos: correo electrónico y contraseña. El sistema deberá validar el correo electrónico por lo menos del tipo XXX@XXX.XXX.XX. En el registro al crear el inicio de sesión deberá ser necesario completar los siguientes campos: Nombre (requerido) Ciudad (requerido) Estado (requerido) País (requerido) Correo electrónico (requerido) Contraseña (requerido) Teléfono (no es necesario).

\footnotetext{
${ }^{30}$ www.technorati.com

${ }^{31}$ www.wefollow.com
} 
Productos y Servicios: Presentación de la cartera de productos y servicios, las historias de éxito para que los clientes puedan decidir si somos o no capaces de satisfacer sus necesidades. Si el cliente lo desea podrá solicitar los detalles del curso donde se deberá abrir un pop up con las descripciones específicas de cada curso.

Descarqas: Se va a crear un área específica para que el usuario realice las descargas Se dividirá en dos (2) partes: una liberada solamente con el login y otra de libre acceso para todos.

Framework: Framework conteniendo la metodología FAST PROJECT desarrollada por la ABC Consultoría. Se trata de un aplicativo donde a través del mismo podrá hacer toda la planificación de su proyecto de una forma rápida, confiable y segura.(conforme las mejores praticas di PMI-Project Management International)

EI FAST PROJECT se puede adaptar a cualquier tipo de empresa para que su aprovechamiento sea cumplido por su organización. No tiene la intención de sofocar a la empresa y sí adaptar la forma de utilizar los métodos y procesos de la empresa. Con eso se vuelve el framework más versátil del mercado.

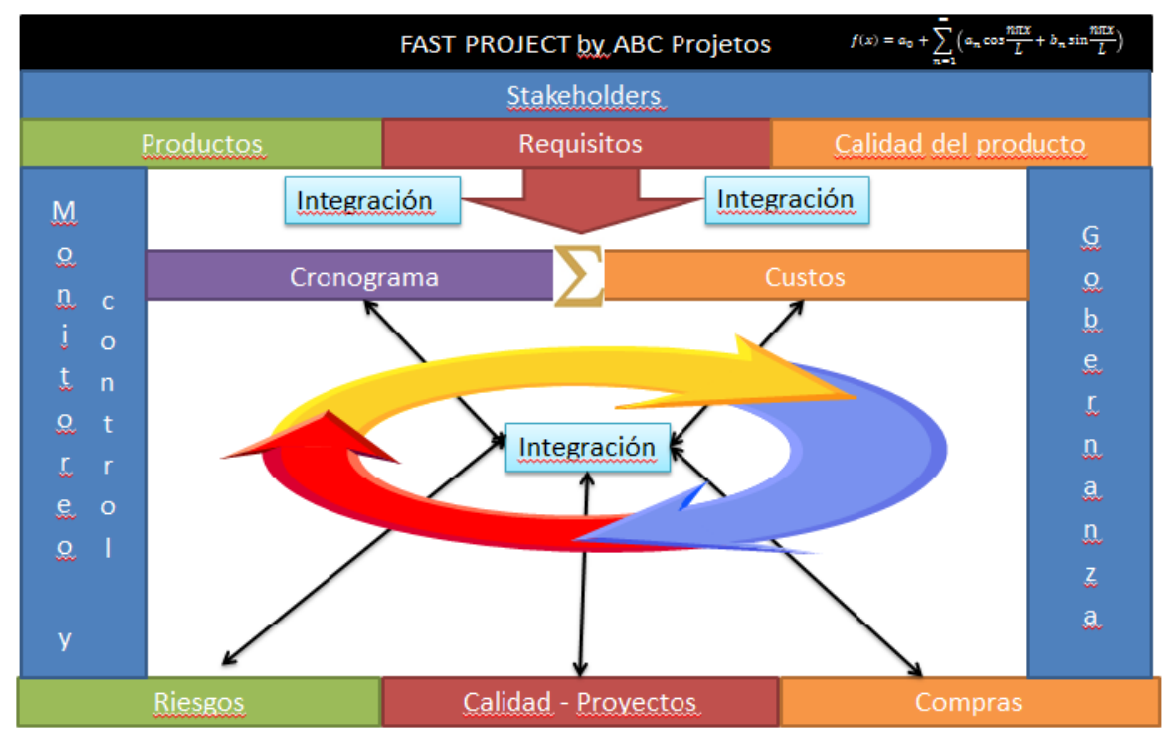

Fuente: Elaboración propia

Ofertas: Relación de ofertas de productos y servicios de la empresa.

Links: Links importantes de softwares y herramientas para la administración de proyectos. En este caso, el sitio web debe permitirnos insertar enlaces sin un límite preestablecido. Se mostrarán en forma de tabla con informaciones del contenido del link. 
Novedades: Es una página que contendrá las campañas que están en el aire, siempre con un aspecto de propagación. Debe ser una página de formato libre que permita dos (2) uploads de textos e imágenes.

Podcasts: Contendrá los podcasts producidos para la empresa para que los clientes y usuarios puedan escuchar. Básicamente serán conferencias y presentaciones hechas por la empresa.

Videocasts: Contendrá los videocasts producidos para la empresa para que los clientes y usuarios puedan ver. Básicamente serán conferencias y presentaciones hechas por la empresa. Será una página preparada exclusivamente para YouTube.

Clientes: Área para que los usuarios dejen sus testimonios sobre los servicios recibidos. También habrá un área para que hable con nosotros y exprese sus opiniones, inquietudes y quejas. El sitio debe permitir que el cliente deje sus declaraciones y que el administrador ponga y quite clientes así como cambiar los contactos indicados en el "hable con nosotros". Provectos: sobre los servicios recibidos. También habrá un área para que hable con nosotros y exprese sus opiniones, inquietudes y quejas. El sitio debe permitir que el cliente deje sus declaraciones y que el administrador ponga y quite clientes así como cambiar los contactos indicados en el hable con nosotros.

Mostraremos los perfiles de la empresa en Facebook y Twitter. Mostraremos también el número de personas que siguen nuestra página en Facebook. En el pie de página mostraremos:

\section{VISITANTE 1.000 .000 facebook. twiltery YouTube}

Así tendremos nuestro sitio web desarrollado y adoptaremos algunas prácticas para volverlo más visible a nuestros clientes.

\subsection{Segunda herramienta: E-mail marketing}

El uso de esta herramienta tiene como objetivo mantener y ampliar las relaciones con los clientes existentes y animarlos a hacer más negocios con nuestra empresa, buscar nuevos clientes, nuestros productos, servicios, promociones y noticias con el fin de hacer las ventas.

La eficacia del email marketing tiene por base los siguientes principios: 
- No depende de las redes sociales y la información contenida en el email queda almacenada en el Apartado de Correos de la persona a la cual nos dirigimos o hasta en su computadora personal. Eso hace que haya más disponibilidad de información para el cliente.

- A algunas personas no les gusta recibir ofertas por la red social y por lo tanto el email marketing para esta situación se muestra más eficaz.

- No todas las personas les gusta o se conectan a redes sociales.

A la vista de estos hechos, crearemos nuestra campaña siguiendo los siguientes pasos:

\subsubsection{Elección del proveedor de servicios de email (ESP)}

Sin un proveedor de servicios no hay como hacer una campaña pues necesitamos hacer la gestión de correos electrónicos, de textos, y validar la eficacia de nuestra campaña.

Tenemos varios proveedores de este tipo de servicio que podemos utilizar.

En los proveedores tenemos la posibilidad de guardar una lista, hacer una selección de la lista, crear y controlar nuestros correos electrónicos, componerlas, enviarlos a nuestro público objetivo y en la secuencia debemos monitorear los resultados de nuestra campaña. En la fase inicial se utilizará la herramienta de E-mail Marketing llamada Constant Contact (creación ) para pruebas ya que nos ofrece sesenta (60) días de ensayo.

\subsubsection{Creación de nuestra lista}

\begin{tabular}{|l|l|}
\hline Artículos & Motivación \\
\hline $\begin{array}{l}\text { Alumnos de la FGV } \\
\text { Vundação Getúlio }\end{array}$ & $\begin{array}{l}\text { Son los alumnos del curso presencial del MBA de proyectos. El número } \\
\text { estimado es de 1.200 alumnos / año. }\end{array}$ \\
\hline $\begin{array}{l}\text { Alumnos del FGV } \\
\text { Online. }\end{array}$ & $\begin{array}{l}\text { Son los alumnos del curso online del MBA donde tenemos también la } \\
\text { probabilidad de hacer servicios de consultoría. El número estimado es } \\
\text { de } 200 \text { alumnos /año }\end{array}$ \\
\hline $\begin{array}{l}\text { Alumnos da DOCTUM } \\
\text { (Faculdade DOCTUM) }\end{array}$ & $\begin{array}{l}\text { Son los alumnos del curso online del MBA donde tenemos la } \\
\text { posibilidad de crear cursos adicionales. El número estimado es de 200 } \\
\text { alumnos/año. }\end{array}$ \\
\hline
\end{tabular}




\begin{tabular}{|l|l|}
\hline $\begin{array}{l}\text { Alumnos de nuestros } \\
\text { capacitaciones. }\end{array}$ & $\begin{array}{l}\text { Son alumnos de nuestros grupos abiertos (Grupos abiertos de } \\
\text { mercado). Estimamos que tendremos } 50 \text { alumnos/año. }\end{array}$ \\
\hline $\begin{array}{l}\text { Personas que se } \\
\text { registraron en nuestro } \\
\text { sitio web. }\end{array}$ & $\begin{array}{l}\text { Son los usuarios que se registraron en nuestro sitio web para hacer } \\
\text { descargas y reciber nuestra Newsletter. Estimamos que en el primer } \\
\text { año este número llegue a } 500 \text { usuarios registrados. }\end{array}$ \\
\hline $\begin{array}{l}\text { Lista de contactos de } \\
\text { inkedin. }\end{array}$ & $\begin{array}{l}\text { Son los contactos del Linkedln de la empresa y también de su socio } \\
\text { Angelo Braga. Estimamos en el primer año } 1.500 \text { conexiones para } \\
\text { Angelo Braga y } 500 \text { conexiones para la empresa. }\end{array}$ \\
\hline $\begin{array}{l}\text { Seguidores del } \\
\text { Facebook. }\end{array}$ & $\begin{array}{l}\text { Son los contactos de Angelo Braga y de la empresa. Estimamos en } \\
1.100 \text { contactos para Angelo Braga y 1.500 contactos para la empresa. } \\
\text { Así tendremos } 2.600 \text { e-mails para contacto. }\end{array}$ \\
\hline Seguidores del Twitter & $\begin{array}{l}\text { Son los seguidores del Twitter de la empresa. Estamos estimando en } \\
200 \text { seguidores en el primer año. }\end{array}$ \\
\hline $\begin{array}{l}\text { Seguidores de nuestro } \\
\text { blog. }\end{array}$ & $\begin{array}{l}\text { Son los seguidores y suscriptores de nuestro blog. Estimamos en el } \\
\text { primer año una cantidad de } 500 \text { seguidores. }\end{array}$ \\
\hline
\end{tabular}

Fuente: Elaboración propia

Con las campañas de email marketing esperamos atraer los siguientes objetivos:

\begin{tabular}{|l|l|l|l|l|}
\hline Medios de comunicación & Emails & Consultoría & Capacitación & Orientaciones \\
\hline Alumnos FGV & 1.200 & 5 & 0 & 0 \\
\hline Alumnos FGV Online & 200 & 1 & 0 & 0 \\
\hline Alumnos Doctum & 200 & 0 & 1 grupo & 10 \\
\hline Alumnos Capacitacións & 50 & 1 & 0 & 0 \\
\hline Registros en el sitio web & 500 & 0 & 1 grupo & 0 \\
\hline LinkedIN & 1.700 & 2 & 0 & 0 \\
\hline Facebook & 2.600 & 1 & 1 grupo & 0 \\
\hline Twitter & 200 & 0 & 1 grupo & 0 \\
\hline Blog & 500 & 1 & 1 grupo & 0 \\
\hline Totales & 7.650 & $\mathbf{1 1}$ & $\mathbf{5}$ & $\mathbf{1 0}$ \\
\hline
\end{tabular}

Fuente: Elaboración Propia 


\subsubsection{Planificación de la campaña}

Inicialmente vamos a enviar un email de presentación de la empresa para crear el vínculo. Presentaremos la empresa, para indicar nuestro sitio web, blog, Facebook y Twitter. Sin embargo, debemos hacer algo atractivo en ese email para llamar la atención de quien lo lee. Después de la presentación inicial elaboraremos un Newsletter mensual con el siguiente contenido: un artículo técnico, un nuevo template y capacitaciones que serán realizadas. Mediremos el desempeño a través de los informes mostrados arriba y también de los feeds RSS (Rich Site Summary) por medio del software free de Google llamado Google Feedburner. ${ }^{32}$

\subsection{Tercera herramienta: $B \log$}

Lo usaremos para añadir otros medios de comunicación, incluyendo imágenes, vídeos, audio y claro el texto. El blog estará accesible por la siguiente dirección:

abcconsultoria.blogspot.com.br.

Nuestro blog estará compuesto de un título, un área central en donde son mostrados los posts (las publicaciones) con su respectiva área para comentarios y también un área de investigación dentro del blog. Por último tendremos barras laterales que son mostradas en una columna donde los usuarios podrán tener algunas opciones de interacción. Las siguientes funciones estarán disponibles en la barra lateral:

\section{Artículo / Función}

Feed RSS: Permite que las personas entren en un link específico para recibir los últimos posts. Será mostrado a los usuarios que nuestro blog es próvido por el Blogger de Google. Mostrar el archivo del blog donde tendremos disponible por año y por mes todos los posts realizados.

Daremos también la opción para que los usuarios sigan nuestro blog a través de emails.

También daremos opción a los usuarios de Google+(herramienta de conectividad di Google) para que sigan nuestro blog.

Mostraremos la cantidad de visualizaciones ocurridas en el blog.

Publicaremos informaciones del mantenedor del blog para contactos futuros.

Fuente: Elaboración propia

${ }^{32}$ www.feedburner.com 
Toda publicación tendrá un área para que los usuarios del blog dejen sus comentarios y también estará disponible una barra donde el usuario podrá ver el post más reciente o ir al inicio del blog. También podrá hacer investigaciones en el blog a través de barras de búsqueda.

En este momento inicial no vamos a insertar blogroll (es una lista de blogs y sitios que recomienda el propietario del blog) para mostrar otros blogs ni mostraremos nuestras publicaciones a través de categorías. Sin embargo, sabemos que cuantas más páginas creamos más entradas y encontrabilidad tendremos en los mecanismos de búsqueda de Google. Por eso usaremos siempre tags con palabras claves que direccionarán nuestra empresa.

Para activar el Feed RSS usamos la herramienta feedburner (es una herramienta que ofrece varias formas de difusión y optimización para la alimentación de tu blog) de Google que se encuentra en la siguiente dirección: feedburner.google.com y nuestro Feed que será encontrado en la siguiente dirección: http://feeds.feedburner.com/ AbcConsultoriaETreinamentoEmGerenciaDeProjetos.

En paralelo daremos la opción a nuestro usuario para que entre en contacto con nosotros a través de un formulario presente en el blog. Vamos a dar la opción a los usuarios para que compartan nuestro blog en Twitter y Facebook. También el contenido será para añadir valor al cliente y estará siempre relacionado a la gerencia de proyectos.

Analizaremos las estadísticas de uso de nuestro blog por medio de la herramienta Google Analytics. Creamos una cuenta en Google Analytics en nombre de ABC Consultoría donde vamos a monitorear. Para monitorear los feeds usaremos la herramienta de Google llamada feedburner disponible en la siguiente dirección: feedburner.google.com. Vamos a buscar el ranking de nuestro blog en la siguiente dirección: http://technorati.com/blogs/directory/.

\subsection{Cuarta herramienta: Podcast, Videocast y Fotos}

Crearemos Podcasts (una forma de transmisión de archivos de audio digitales) y Videocast (una forma de transmisión de archivos de video digitales) a medida en que la empresa vaya desarrollando capacitaciones. Tendremos como base el Youtube para hacer la publicación 
de nuestros documentos. La página ya está creada y será usado el login del Gmail del director de la empresa para hacer el gerenciamiento de los vídeos.

La regla que usaremos para construir nuestros videocasts y podcasts tienen como base la creación de videos cortos que seguirán la siguiente regla de duración:

\begin{tabular}{|l|l|}
\hline Parte & Duración \\
\hline Introducción & $00: 30$ \\
\hline Contenido & $05: 00$ a 10:00 \\
\hline Encerramiento & $00: 30$ \\
\hline
\end{tabular}

Fuente: Elaboración propia

Para hacer la edición de sonido vamos a usar el software Audacity $^{33}$ que es un software free.

No usaremos músicas por cuestiones relacionadas a derechos autorales. En caso de que algún día sea necesario el uso de música, solicitaremos el permiso de uso de la misma en el sitio web especifico. ${ }^{34}$

Para optimizar nuestro trabajo adoptaremos las siguientes herramientas:

- Vamos a usar el recurso TwitVid (Online service para envio di videos desde tu webcam o su computadora y utilizarlos en su twitadas) para compartir el vídeo en Twitter.

- Vamos a usar Youtube Autoshare ${ }^{35}$ para linkar las actividades de Youtube, Facebook y Twitter

- Vamos a usar la herramienta Friend $F e e d^{36}$ para incluir nuestro canal al añadidor de vídeo y después importar el feed para Facebook haciendo intercambio normal o usando el propio feed creado para el blog y sitio web.

a Para incluir los vídeos de Youtube en la página de Facebook vamos a usar la herramienta de intercambio normal de Facebook

\footnotetext{
${ }^{33} \mathrm{http}$ //audacity.sourceforge.net

${ }^{34}$ www.musicalley.com

${ }^{35} \mathrm{http}: / /$ www.youtube.com/account\#sharing/activity

${ }^{36}$ www.friendfeed.com
} 
En lo que respecta a las fotos, publicaremos las mismas en la página de Facebook y no usaremos Picasa (es un programa que incluye la edición digital de fotografías y cuya principal función es organizar la colección de fotos digitales en el computer) para compartir fotos. Para medir los resultados vamos a usar siempre Google Analytics.

\section{5- Quinta herramienta: Redes sociales}

Estaremos presentes en las redes sociales Facebook, Twitter y Linkedln.

\section{- Facebook}

El nombre de nuestra página en Facebook será ABC Consultoría en Gestión de Proyectos y en ella publicaremos los siguientes contenidos:

- Las mismas publicaciones hechas en el blog, es decir, los artículos con alto valor añadido para los clientes y que estarán disponibles en los dos medios de comunicación.

- Las fotos de las capacitaciones realizadas por la empresa.

- Las promociones que la empresa hará para conquistar nuevos clientes.

La página de Facebook ya está creada, ya tenemos 375 seguidores y por lo tanto ya podrá ser visualizada por todos con el nombre creado. Para medir la eficacia de nuestra empresa en Facebook vamos a usar las herramientas gestión de la página de facebook ${ }^{39} \mathrm{y}$ solicitaremos view insights (herramienta para para medir el éxito de tu página de fans) para medir como está el uso de nuestra página. De esa manera conseguiremos medir como está nuestro rendimiento en Facebook.

\section{- Linkedln}

Por el hecho de que tenemos más de 1.460 conexiones con el director y principal responsable técnico de la empresa optamos por usar como medio de comunicación inicial la cuenta de Angelo Braga que por la cantidad de contactos existentes facilitará la divulgación de la propia empresa. De esa forma vamos a direccionar los contactos del Linkedln inicialmente solamente en el contacto de Angelo Jose Albino Braga que es el presidente y fundador de la empresa ABC Consultoria y Capacitación en Administración de Proyectos. Vamos a publicar nuestras promociones a través de mensajes para todos los contactos existentes en Facebook.

\footnotetext{
${ }^{39}$ https://www.facebook.com/ABCConsultoriaemProjetos
} 


\section{- Twitter}

Inicialmente no crearemos una nueva cuenta en Twitter para la empresa. Será usada la cuenta de Angelo Braga, presidente de la empresa de la misma forma que hicimos en Linkedln.

Para hacer las mediciones de como estamos en relación a nuestro desempeño en Twitter mediremos la eficacia de nuestra comunicación por medio de las siguientes herramientas:

- Twitter Counter (es un sitio de Twitter que muestra algunas estadísticas de tu perfil): para saber la cantidad de seguidores que tenemos. No definimos aún una cantidad mínima.

- $\quad$ Twitteranalyzer ${ }^{40}$ (ofrece datos sobre cualquier cuenta twitter: sexo, origen, edad y tipo de profesional quién accede a tu cuenta) nos ayudará a comprender más al respecto de nuestros seguidores. Así podemos direccionar mejor nuestra relación con ellos.

- Mediremos la efectividad de nuestra comunicación con la cantidad de retuites(retransmitir un mensaje recibido) a través del uso de la herramienta: tweetmeme.com/about/analytics

- Vamos a verificar nuestro ranking a través del uso de las herramientas Twitterrank $^{41}$ (analiza la posición de nuestro twitter) y Twittergrader $^{42}$ (herramienta que utiliza los criterios para la elaboración de la nota y posicionamiento en el ranking general de Twitter) así como también consultaremos nuestra presencia en directorios a través de la herramienta Wefollow ${ }^{43}$ (Un directorio de personas prominentes organizada por intereses).

\section{Estrategia para el crecimiento en América del Sur}

La forma que encontré para que la empresa crezca en América del Sur $\theta$ y a través de la creación de alianzas. Como la empresa está en la etapa inicial no se puede tener un número grande de alianzas y debo enfocar en las más atractivas y en los mayores mercados.

Así, que voy a centrar en tres (3) grandes ciudades fuera de Brasil: Buenos Aires, Santiago y Montevideo.

\footnotetext{
${ }^{40}$ www.twitalyzer.com

${ }^{41}$ https://twitter.com/rank1official; https://twitter.com/Tweet_Ranck

${ }^{42} \mathrm{https} / / /$ marketing.grader.com/

${ }^{43}$ www.wefollow.com
} 
De esta manera será posible iniciar la introducción en América del Sur a través de alianzas que revenderán productos y servicios de capacitación y consultoría en gestión de proyectos. Sin embargo, para abrir la posibilidad de la creación de alianzas es necesario que la empresa demuestre valor añadido para los posibles socios.

La estrategia para adquirir y poder demonstrar este valor añadido es traer algo innovador y de representación exclusiva en América del Sur por nuestra empresa. Para eso, me voy al Seminario Mundial de Project Management Institute (PMI) en los Estados Unidos en Octubre de 2015 donde en este seminario buscaré conocer nuevas soluciones, nuevos productos y formas de trabajo y en el evento establecer socios de representación de estos productos de forma exclusiva en América del Sur.

Una vez que tengo la exclusividad de la representación de productos en América del Sur, buscaré tres (3) socios en Buenos Aires, tres 3 en Santiago y tres 3 en Montevideo. Así, conseguiré establecer una alianza con, por lo menos, uno de estos 3 socios en cada ciudad para revender los productos o servicios en los países destinos. Así, demostrando valor añadido, con nuevos productos innovadores, creo que será más fácil conseguir tales alianzas y así aumentar la participación en el mercado.

Además de eso, el sitio web también estará disponible en los idiomas portugués y español, lo que facilitará el acceso por todos los países con los cuales deseo hacer la sociedad.

Pretendo establecer las sociedades / alianzas en el primer año de existencia de la empresa siguiendo el cronograma abajo mostrado:

\begin{tabular}{|l|l|}
\hline Actividad & Período de realización \\
\hline Participación congreso PMI en los Estados Unidos & $1^{\circ}$. mes \\
\hline $\begin{array}{l}\text { Construcción de los acuerdos de representación con } \\
\text { empresas en los Estados Unidos }\end{array}$ & $2^{\circ} / 3^{\circ} / 4^{\circ}$.meses \\
\hline Firma de los acuerdos & $5^{\circ}$. mes \\
\hline Búsqueda de los socios en Buenos Aires & $6^{\circ} / 7^{\circ} / 8^{\circ} / 9^{\circ} / 10^{\circ}$ meses \\
\hline Firma del contrato con socios en Buenos Aires & $11^{\circ} / 12^{\circ}$ meses \\
\hline Búsqueda de los socios en Santiago & $6^{\circ} / 7^{\circ} / 8^{\circ} / 9^{\circ} / 10^{\circ}$ meses \\
\hline Firma del contrato con socios en Santiago & $11^{\circ} / 12^{\circ}$ meses \\
\hline Búsqueda de los socios en Montevideo & $6^{\circ} / 7^{\circ} / 8^{\circ} / 9^{\circ} / 10^{\circ}$ meses \\
\hline Firma del contrato con socios en Montevideo & $11^{\circ} / 12^{\circ}$ meses \\
\hline
\end{tabular}

Fuente: Elaboracion propia 
De esa manera conseguiré alcanzar los objetivos de la empresa en lo que respecta a la introducción de la misma en el escenario de negocios para América del Sur.

\section{Análisis de viabilidad de la creación de la empresa, forma de operación y manutención}

Para hacer el análisis de la viabilidad de nuestra empresa buscaremos respuesta a las siguientes preguntas.

\begin{tabular}{|l|l|}
\hline Cuestionamiento & Respuesta \\
\hline $\begin{array}{l}\text { ¿Qué objetivos y propósitos de } \\
\text { marketing tenemos? }\end{array}$ & $\begin{array}{l}\text { Alcanzar público 100\% a través de marketing digital } \\
\text { por Internet. }\end{array}$ \\
\hline $\begin{array}{l}\text { ¿Qué mercado deseo alcanzar y } \\
\text { conquistar? }\end{array}$ & $\begin{array}{l}\text { Mercado brasileño y sur-americano que tiene interés } \\
\text { en gerencia de proyectos, ya sea consultoría o } \\
\text { capacitación. }\end{array}$ \\
\hline ¿Dónde está este mercado? & $\begin{array}{l}\text { Gran parte es proveniente de alumnos que hacen } \\
\text { capacitaciones en Gerenciamiento de Proyectos y } \\
\text { necesitan complementación a través de consultoría. }\end{array}$ \\
\hline $\begin{array}{l}\text { ¿Cuáles herramientas utilizar para } \\
\text { alcanzar mis objetivos? }\end{array}$ & $\begin{array}{l}\text { Herramientas de marketing digital conforme } \\
\text { descripción en el capítulo anterior. }\end{array}$ \\
\hline $\begin{array}{l}\text { ¿Cómo evaluar los resultados } \\
\text { perseguidos? }\end{array}$ & $\begin{array}{l}\text { Validaremos los resultados a través de la medición } \\
\text { financiera del desempeño de la empresa. }\end{array}$ \\
\hline
\end{tabular}

Fuente: Elaboración propia

Sin embargo, para alcanzar el mercado de América del Sur, debemos hacer la prospección de alianzas y socios, socios estos que deberán ser encontrados y desarrollados en las ciudades de Buenos Aires, Santiago y Montevideo.

\section{1 - Precios}

Debemos hacer el análisis del precio de servicios y sus variaciones para formar nuestro precio. Para definir nuestros precios primeramente debemos establecer cuáles son los costos de implantación de la empresa y los de gestión de la empresa. A continuación los mostramos. 
Implantación:

\begin{tabular}{|l|l|l|l|l|}
\hline Artículo & Cant & Costo(R\$) & Total & Mes de pago \\
\hline Computadora & 1 & $2.500,00$ & $2.500,00$ & 1 \\
\hline Proyector & 1 & $1.200,00$ & $1.200,00$ & 1 \\
\hline Layout sitio web & 1 & $3.000,00$ & $3.000,00$ & 1 \\
\hline Seminario Internacional PMI & 1 & $10.000,00$ & $10.000,00$ & 1 \\
\hline Prospección de socios & 1 & $5.000,00$ & $5.000,00$ & 1 \\
\hline Programación sitio web & 1 & $2.500,00$ & $2.500,00$ & 1 \\
\hline Contratación dominio & 1 & 40,00 & 40,00 & \\
\hline Total & & & $24.240,00$ & \\
\hline
\end{tabular}

Fuente: elaboración propia

Ingresos - Valor mensual

\begin{tabular}{|l|l|r|r|}
\hline Artículo & Cant. & Costo(R\$) & \multicolumn{1}{|l|}{ Total } \\
\hline Capacitaciones abiertas & 1 & 300,00 & 300,00 \\
\hline Clases in Company & 1 & $12.000,00$ & $12.000,00$ \\
\hline Servicios de consultoría & 1 & $5.000,00$ & $5.000,00$ \\
\hline Total & & & $17.300,00$ \\
\hline
\end{tabular}

Fuente: Elaboración propia

Costos de Gestión - Valor mensual

\begin{tabular}{|l|l|r|r|}
\hline Artículo & Cant. & Costo(R\$) & \multicolumn{1}{|l|}{ Total } \\
\hline Manutención del sitio web & 1 & 300,00 & 300,00 \\
\hline Link Internet & 1 & 70,00 & 70,00 \\
\hline Gastos con viajes nacionales & 1 & 500,00 & 500,00 \\
\hline Gastos con viajes internacionales & 1 & $4.000,00$ & $4.000,00$ \\
\hline Manutención del dominio & 1 & 30,00 & 30,00 \\
\hline Contabilidad & 1 & 400,00 & 400,00 \\
\hline Impuestos & 1 & 600,00 & 600,00 \\
\hline Tarifas bancarias & 1 & 80,00 & 80,00 \\
\hline Funcionario de administración & 1 & $2.000,00$ & $2.000,00$ \\
\hline Remuneración socio principal & 1 & $5.000,00$ & $5.000,00$ \\
\hline Herramientas de marketing & 1 & 400,00 & 400,00 \\
\hline Certificado digital & 1 & 50,00 & 50,00 \\
\hline Manutención da lista de email & 1 & 500,00 & 500,00 \\
\hline Contratación de publicidad & 1 & 500,00 & 500,00 \\
\hline Total & & & $\mathbf{1 4 . 4 3 0 , 0 0}$ \\
\hline
\end{tabular}

Fuente: Elaboración propia

De la forma arriba mostrada conseguimos una tasa de retorno de: 


\begin{tabular}{|l|l|l|l|l|l|l|l|}
\hline Mes & Ingresos & Gastos & Delta & Mes & \multicolumn{1}{l|}{ Ingresos } & \multicolumn{1}{l|}{ Gastos } & Delta \\
\hline 1 & $17.300,00$ & $24.240,00$ & $-6.940,00$ & 18 & $17.300,00$ & $14.430,00$ & $2.870,00$ \\
\hline 2 & $17.300,00$ & $14.430,00$ & $2.870,00$ & 19 & $17.300,00$ & $14.430,00$ & $2.870,00$ \\
\hline 3 & $17.300,00$ & $14.430,00$ & $2.870,00$ & 20 & $17.300,00$ & $14.430,00$ & $2.870,00$ \\
\hline 4 & $17.300,00$ & $14.430,00$ & $2.870,00$ & 21 & $17.300,00$ & $14.430,00$ & $2.870,00$ \\
\hline 5 & $17.300,00$ & $14.430,00$ & $2.870,00$ & 22 & $17.300,00$ & $14.430,00$ & $2.870,00$ \\
\hline 6 & $17.300,00$ & $14.430,00$ & $2.870,00$ & 23 & $17.300,00$ & $14.430,00$ & $2.870,00$ \\
\hline 7 & $17.300,00$ & $14.430,00$ & $2.870,00$ & 24 & $17.300,00$ & $14.430,00$ & $2.870,00$ \\
\hline 8 & $17.300,00$ & $14.430,00$ & $2.870,00$ & 25 & $17.300,00$ & $14.430,00$ & $2.870,00$ \\
\hline 9 & $17.300,00$ & $14.430,00$ & $2.870,00$ & 26 & $17.300,00$ & $14.430,00$ & $2.870,00$ \\
\hline 10 & $17.300,00$ & $14.430,00$ & $2.870,00$ & 27 & $17.300,00$ & $14.430,00$ & $2.870,00$ \\
\hline 11 & $17.300,00$ & $14.430,00$ & $2.870,00$ & 28 & $17.300,00$ & $14.430,00$ & $2.870,00$ \\
\hline 12 & $17.300,00$ & $14.430,00$ & $2.870,00$ & 29 & $17.300,00$ & $14.430,00$ & $.870,00$ \\
\hline 13 & $17.300,00$ & $14.430,00$ & $2.870,00$ & 30 & $7.300,00$ & $14.430,00$ & $2.870,00$ \\
\hline 14 & $17.300,00$ & $14.430,00$ & $2.870,00$ & 31 & $17.300,00$ & $14.430,00$ & $2.870,00$ \\
\hline 15 & $17.300,00$ & $14.430,00$ & $2.870,00$ & 32 & $17.300,00$ & $14.430,00$ & $2.870,00$ \\
\hline 16 & $17.300,00$ & $14.430,00$ & $2.870,00$ & 33 & $7.300,00$ & $14.430,00$ & $2.870,00$ \\
\hline 17 & $17.300,00$ & $14.430,00$ & $2.870,00$ & 34 & $17.300,00$ & $14.430,00$ & $2.870,00$ \\
\hline & Retorno & & & 35 & $17.300,00$ & $14.430,00$ & $2.870,00$ \\
\hline & $1^{\circ}$. año & $40 \%$ & 36 & $17.300,00$ & $14.430,00$ & $2.870,00$ \\
\hline & 36 meses & $41 \%$ & & Totales & $622.800,00$ & $529.290,00$ & $93.510,00$ \\
\hline
\end{tabular}

Fuente: Elaboración propia

Para definir nuestros precios consideraremos los siguientes puntos:

¿QQué valor añadido generamos a nuestros clientes?

口 ¿Cuál es nuestro objetivo en la formación del precio?: maximizar el lucro o ganar mercado ofertando el precio más bajo.

¿QQué podemos usar como estrategia para establecer nuestros honorarios? Costos mínimos, costos fijos y margen de lucro que deseamos tener.

¿ ¿Cuál será nuestra táctica para formar los precios?

¿ ¿Cómo cobraremos y calcularemos nuestros honorarios con más eficacia?

Formaremos precios con base en los costos, en la competencia, en la demanda y por servicio prestado. La forma como formaremos los precios está mostrada en el Anexo 1.

\section{2 - Cobranza de los honorarios}

En nuestro caso específico vamos a establecer las siguientes formas de cobranza de nuestros honorarios: 
Consultoría: cobraremos tiempo + gastos + horas trabajadas.

- Capacitaciones: será cobrado un precio cerrado por alumno.

\section{3 - Táctica para establecer los honorarios}

Ya sabemos que deberemos cobrar un valor / hora mínimo de US $\$ 90,00$ para que tengamos el lucro deseado. Sin embargo, podremos ofrecer descuentos si:

- Se contrata un número mayor de servicios o alumnos.

- La demanda es baja y tenemos horas de trabajo ociosas.

a Cuando estamos trabajando en proyectos sociales o de gran valor social.

Por otro lado, podemos cobrar precios mayores cuando existan las siguientes condiciones:

- El cliente solicita que el trabajo sea ejecutado en períodos de tiempo reducidos.

- Solamente nuestra empresa es capaz de ofrecer el servicio.

- Cuando tenemos exposición a riesgos de reputación de nuestra empresa.

\section{4 - Estrategias para retención y relacionamientos}

Queremos retener nuestros clientes para mantener nuestro crecimiento, porque:

- Los clientes de nuestra base representan mayor probabilidad de contratar nuevamente nuestros servicios debido a la confianza ya adquirida.

- El costo para satisfacer esos clientes es menor que de los nuevos clientes, ya que no tendremos inversiones extras para este artículo.

- Después de tener la confianza de la empresa podemos expandir nuestro abanico de servicios.

L Los clientes a medida que nos conocen perciben un mayor valor en nuestros servicios y hace que él acepte nuestros valores y reajustes más fácilmente.

Los clientes satisfechos nos indican y nos recomiendan para otros clientes haciendo con que nuestros costos de captación sean reducidos.

Por las razones arriba expuestas, nos enfocaremos fuertemente en la manutención de los clientes ya conquistados enfocando en los componentes:

- Confianza: es el principio básico de todo relacionamiento de servicios. 
- Conocimiento al respecto de los clientes: el conocimiento del negocio del cliente y de su operación bien como de sus fuerzas y debilidades hace que podamos añadir más valor a los servicios prestados.

- Accesibilidad para los clientes: debemos tener disponible los teléfonos, e-mails y otros medios de comunicación para que nos encuentre siempre que necesite. Con lo arriba expuesto, entendemos que nuestra empresa funcionará adecuadamente y también será competitiva ante el mercado escogido.

\section{Conclusiones}

Con la propuesta del tipo de empresa que deseamos crear e invertir en ella, tomamos algunas decisiones que creemos serán las mejores frente a los escenarios con los cuales nos enfrentamos.

El punto de partida es que deseamos crear una empresa para un público altamente especializado y capacitado, público que está acostumbrado con el uso de Internet y diversas herramientas de informática.

Como tenemos pocos recursos para la inversión inicial, optamos por desarrollar una empresa $100 \%$ con base en Internet y con todo su proceso de marketing con base en marketing digital que sabiamente es el marketing de menor costo.

Después de esa decisión estudiamos qué herramientas de marketing digital deberíamos usar, que cuidados deberíamos tener para conseguir una alta efectividad en el abordaje de nuestros clientes y finalmente después de los estudios hechos, diseñamos nuestro modelo de negocio/empresa totalmente direccionado en el uso de la Internet. Comprendemos que este es el modelo ideal para quien desea entrar en el mercado, no dispone de muchos recursos y posee clientes disponibles para ser encontrados y localizados a través de Internet.

Ya que nuestra empresa ofrecerá solamente servicios, nos enfocamos también en cómo establecer nuestros precios privilegiando la visión de los clientes y mercado de servicios y también la estrategia y táctica para manutención de nuestros mercados conquistados. 
Con eso concluimos que nuestra decisión fue acertada, que escogemos las herramientas de bajo costo y alta eficiencia y que estamos listos para ir al mercado y buscar el crecimiento que deseamos. Es decir, el marketing digital es una realidad que llegó para quedarse pues a cada día aumenta el número de personas conectadas a Internet.

\section{Anexos}

\section{Precio con base en los costos}

En esa modalidad necesitamos entender nuestros costos, determinar un factor de multiplicación para generar nuestro lucro. Para eso tenemos la siguiente ecuación: $\mathrm{C}=$ costo anual de la manutención del equipo de profesionales.

$\mathrm{N}=$ número de profesionales.

$\mathrm{S}=$ remuneración media pagada por hora.

$\mathrm{H}=$ número de horas que cada profesional debe trabajar por año. $\mathrm{C}=\mathrm{H} \times \mathrm{N} \times \mathrm{S}$

\begin{tabular}{|c|c|c|}
\hline Variable & Valor & Explicación \\
\hline $\mathrm{H}$ & $2.112,00$ & 8 horas / día $\times 22$ días / mes $\times 12$ meses \\
\hline $\mathrm{S}$ & 56,82 & $\mathrm{R} \$ 10.000 / 176$ horas mensuales \\
\hline $\bar{N}$ & 1,00 & Estimamos solamente 1 profesional \\
\hline $\mathrm{C}$ & $120.000,00$ & $\mathrm{C}=\mathrm{H} \times \mathrm{N} \times \mathrm{S}$ \\
\hline
\end{tabular}

Fuente: Elaboración propia

En seguida debemos calcular los costos fijos anuales:

$\mathrm{F}=$ costo fijo anual

\begin{tabular}{|l|l|l|}
\hline Variable & Valor & Explicación \\
\hline $\begin{array}{l}\mathrm{F} \text { (costo fijo } \\
\text { anual) }\end{array}$ & $143.160,00$ & $\mathrm{R} \$ 11.930 \times 12$ meses \\
\hline
\end{tabular}

Fuente: Elaboración propia

Finalmente vamos a calcular el precio considerando la siguiente ecuación:

$\mathrm{M}=$ factor multiplicador $/ \mathrm{P}=$ índice de productividad $/ \mathrm{R}=$ receta total anual $\mathrm{R}=\mathrm{C} \times \mathrm{M} \times \mathrm{P}$

\begin{tabular}{|l|l|l|}
\hline Variable & Valor & Explicación \\
\hline P & 0,7 & Índice productividad media \\
\hline C & $120.000,00$ & Ya calculado \\
\hline
\end{tabular}

Fuente: Elaboración propia 
$\mathrm{R}=120.000 \times \mathrm{M} \times 0,7 \rightarrow \mathrm{R}=84.000 \times \mathrm{M}$

Por último vamos a calcular los lucros:

$Z=$ lucro deseado $\rightarrow Z=R-C-F \rightarrow Z=84.000 x M-120.000-143.160$

Vamos a definir que deseamos un lucro de $R \$ 100.000,00$. Así la ecuación quedará:

$100.000=84.000 \times M-120.000-143.160 \rightarrow M=363.130 / 84.000 \rightarrow M=4,32$

Así el factor multiplicador para nuestros costos es de 4,32 para que tengamos el lucro deseado.

Sin embargo, podemos hacer también la cuenta inversa. Vamos a aplicar un factor de 2,5 y una productividad de 0,7 . Así nuestra receta sería:

$\mathrm{R}=120.000 \times 4,32 \times 0,7=362.880 /$ ano

Valor hora que debemos cobrar: $362.880 / 2.112=\mathbf{R} \$ 171,81 /$ hora

De esa forma concluimos que todo y cualquier servicio que hagamos debemos cobrar $\mathbf{R} \$ 172,00$ / hora trabajada para tener el lucro deseado.

\section{Remuneración con base en la competencia}

Usaremos ese método para las situaciones donde tendremos fuerte competencia. Para este caso específico tendremos como base el precio de la competencia y a partir de ahí haremos el análisis de la viabilidad de la situación. Obviamente para que seamos competitivos disminuiremos nuestro precio en cerca del 10\% del menor precio de la competencia. Para eso, obviamente, precisaremos de tener volúmenes de alumnos conforme mostrado a seguir y que trata de un curso.

Curso: Preparación para la Certificación PMP (Realización en Brasil)

Duración: 40 horas

Modalidad: Presencial

Precio medio de mercado: $\mathrm{R} \$ 1.250$ / alumno

\begin{tabular}{|l|c|l|c|}
\hline \multicolumn{2}{|l|}{ Costos Generales } & \multicolumn{2}{l|}{ Costos por alumno } \\
\hline Descripción & Costo & Descripción & Costo \\
\hline $\begin{array}{l}\text { Alquiler del aula - 40 } \\
\text { horas }\end{array}$ & $2.000,00$ & $\begin{array}{l}\text { Material } \\
\text { didáctico }\end{array}$ & 200,00 \\
\hline Instructor & $4.800,00$ & $\begin{array}{l}\text { CD con } \\
\text { simulados }\end{array}$ & 10,00 \\
\cline { 1 - 3 } Equipamientos & 200,00 & Total & $\mathbf{2 1 0 , 0 0}$ \\
\hline Total & $\mathbf{7 . 0 0 0 , 0 0}$ & \multicolumn{3}{|l}{} \\
\cline { 1 - 2 } & \multicolumn{3}{|l}{}
\end{tabular}




\begin{tabular}{|l|l|l|l|l|l|l|}
\hline \multicolumn{2}{|l|}{ Análisis de viabilidad } \\
\hline $\begin{array}{l}\text { Cant. } \\
\text { alumnos }\end{array}$ & $\begin{array}{l}\text { Costos } \\
\text { Generales }\end{array}$ & $\begin{array}{l}\text { Costos por } \\
\text { alumno }\end{array}$ & $\begin{array}{l}\text { Costo } \\
\text { total }\end{array}$ & Factor & $\begin{array}{l}\text { Precio por } \\
\text { alumno }\end{array}$ & Situación \\
\hline 5 & $7.000,00$ & $1.050,00$ & $8.050,00$ & 1,4 & $2.254,00$ & Inviable \\
\hline 10 & $7.000,00$ & $2.100,00$ & $9.100,00$ & 1,4 & $1.274,00$ & Viable \\
\hline 12 & $7.000,00$ & $2.520,00$ & $9.520,00$ & 1,4 & $1.110,67$ & Viable \\
\hline 15 & $7.000,00$ & $3.150,00$ & $10.150,00$ & 1,4 & 947,33 & Viable \\
\hline
\end{tabular}

Fuente: Elaboración propia

Observamos que en este caso solamente a partir de 10 alumnos es que el grupo se viabilizará. Para alcanzar una gran cantidad de alumnos haremos promociones en el Groupon, Peixe Urbano, etc. Indicaremos el valor de R\$1.100 pero tendremos que tener mínimo 20 inscritos para abrir el grupo. Así conseguiremos alcanzar nuestra meta de costo $x$ precio ofertado $\mathrm{x}$ lucro.

Curso: Preparación para la Certificación PMP (Realización fuera de Brasil)

Duración: 40 horas

Modalidad: Presencial

Precio medio de mercado: $\mathrm{R} \$ 1.250$ / alumno

\begin{tabular}{|l|c|l|r|}
\hline \multicolumn{2}{|l|}{ Costos Generales } & \multicolumn{2}{l|}{ Costos por alumno } \\
\hline Descripción & Costo & Descripción & Costo \\
\hline Alquiler del aula - 40 horas & $2.000,00$ & Material didáctico & 200,00 \\
\hline Instructor & $4.800,00$ & CD con simulados & 10,00 \\
\hline Viajes & $6.000,00$ & Total & $\mathbf{2 1 0 , 0 0}$ \\
\cline { 1 - 2 } Equipamientos & 200,00 & \multicolumn{2}{|}{} \\
\cline { 1 - 2 } Total & $\mathbf{1 3 . 0 0 0 , 0 0}$ & \multicolumn{2}{|l}{}
\end{tabular}

Fuente: Elaboración propia

Análisis de viabilidad

\begin{tabular}{|l|l|l|l|l|l|l|}
\hline $\begin{array}{l}\text { Cant. de } \\
\text { alumnos }\end{array}$ & $\begin{array}{l}\text { Costos } \\
\text { Generales }\end{array}$ & $\begin{array}{l}\text { Costos por } \\
\text { alumno }\end{array}$ & $\begin{array}{l}\text { Costo } \\
\text { total }\end{array}$ & Factor & $\begin{array}{l}\text { Precio por } \\
\text { alumno }\end{array}$ & Situación \\
\hline 5 & $13.000,00$ & $1.050,00$ & $14.050,00$ & 1,4 & $3.934,00$ & Inviable \\
\hline 10 & $13.000,00$ & $2.100,00$ & $15.100,00$ & 1,4 & $2.114,00$ & Inviable \\
\hline 12 & $13.000,00$ & $2.520,00$ & $15.520,00$ & 1,4 & $1.810,67$ & Inviable \\
\hline 15 & $13.000,00$ & $3.150,00$ & $16.150,00$ & 1,4 & $1.507,33$ & Inviable \\
\hline 20 & $13.000,00$ & $4.200,00$ & $17.200,00$ & 1,4 & $1.204,00$ & Viable \\
\hline
\end{tabular}

Fuente: Elaboración propia 
Observamos que en este caso solamente a partir de 20 alumnos es que el grupo se viabilizará. Para alcanzar una gran cantidad de alumnos haremos promociones usando las herramientas disponibles en cada región geográfica en que estemos ofertando el servicio.

\section{$\underline{\text { Remuneración por el servicio dado }}$}

Aplicaremos este tipo de remuneración para los servicios de consultoría donde cobraremos un valor / hora mínimo de $\mathrm{R} \$ 180,00$ (demostrado anteriormente) versus la cantidad de horas contratadas por el cliente para consultoría.

De esa forma estaremos cobrando nuestra remuneración por el servicio prestado de venta del conocimiento, es decir, lo que está en juego es nuestra experiencia y el valor agregado que llevaremos para nuestro cliente.

\section{Precio de acuerdo a la demanda}

Si percibimos que hay un aumento de la demanda por nuestros servicios considerando que la percepción del valor de los clientes por nuestro servicio aumentó. Así podremos aumentar nuestro valor / hora de referencia que actualmente es de $\mathrm{R} \$ 180,00$.

\section{Bibliografía y fuentes consultadas}

\section{Libros, por autor}

- CHAFFER, Dave. (2008) Emarketing excellence: planning and optimizing your digital marketing. Oxford: Editora Butterworth Heinemann - RoutLedge.

- Goldman, Aaron. (2011) Tudo o que sei sobre marketing aprendi com o Google. São Paulo: Editora Saraiva.

- Harte, Laurence. (2012) Introduction to Internet Marketing: Search Engine Optimization, Adword Marketing, Email Promotion, and Affiliate Programs.

- JANTSCH, John. (2007) Marketing de baixo custo e alto impacto: duct tape marketing.Rio de Janeiro: Editora Thomas Nelson Brasil. 
- LAMB, Charles W.; HAIR, Joseph F.; McDaniel, Carl;Marketing 11e. CENGAGE Learning.

- Lima, Rosalvo. (2006) O ABC da empresa de serviços.São Paulo: Futura.

- Parasuraman, A;COLBY, Charles L. (2002) Marketing para produtos inovadores. Porto Alegre: Editora Bookman.

- Kotler, Philip Y Kevin Lane Keller. (2006) Administração de Marketing. São Paulo: Editora Pearson Prentice Hall.

- Kotler, Philip (1999). Principios de Marketing. São Paulo: Editora Pearson Prentice Hall.

- Kotler, Philip / Hayes, Thomas / Bloom, Paulo N. (2002)Marketing de Serviços Profissionais. São Paulo: Editora Manole

- París, José Antonio. (2009) Marketing Esencial - Um Enfoque Latinoamericano.Buenos Aires. Editora Errepar SA

- Reed, Jon. (2012) Marketing Online - Como usar sites, blogs, redes sociais e muito mais. São Paulo, Editora Lafonte.

- Torres, Claudio. (2009) A Bíblia do Marketing Digital. São Paulo: Editora Novatec Editora.

- Vaz, Conrad Adolpho. (2011) Os 8 Ps do marketing digital: o seu guia estratégico de marketing digital. São Paulo: Editora Novatec Editora

- Anderson, Chris. (2004) Wired Magazine

- Anderson, Chris. (2008) The Long Tail. Estados Unidos: Hyperion Books

Internet: Sitios web consultados

- Clicky, "Real Time Web Analytics", accedido el 02/072013 en http://clicky.com/

- Technorati, "Site para medir o ranking do nosso blog", accedido el 25/06/2013 en http://technorati.com/blogs/directory/

- Youtube, "Youtube broadcast yourself", accedido em 02/02/20313 en http://www.youtube.com/

- Facebook, "Ferramenta para criação da página da empresa, gerenciar fãs e divulgação dos eventos da empresa", accedido el 02/04/2013 en https://www.facebook.com/

- Twitter, "Microblog para divulgação dos eventos da empresa", accedido el 02/04/2013 en https://twitter.com/ 
- Bitly, "Do more with your links! The new way to bookmark, organize, and share the things you care about online.", accedido el 02/04/2013 en https://bitly.com/

- Backtweets, "Search for links on twitter", accedido el 02/04/2013 en http://backtweets.com/

- Twittercounter, "Mostra o histórico de seguidores", accedido el 02/04/2013 en http://twittercounter.com/

- Tweetstats, "Mostra o número de tweets por dia", accedido el 02/04/2013 en http://www.tweetstats.com//

- Tweeteffect, "Ferramenta para verificar o efeito do que falamos", accedido el 02/04/2013 en http://tweeteffect.com/

- E-mail Marketing, "Ferramenta para fazer marketing através do uso de e-mail com gestão de listas e conteúdo de e-mail", accedido el 18/04/2013 en www.campaignmonitor.com

- E-mail Marketing, "Ferramenta para fazer marketing através do uso de e-mail com gestão de listas e conteúdo de e-mail", accedido el 18/04/2013 en www.dotmailer.com,

- E-mail Marketing, "Ferramenta para fazer marketing através do uso de e-mail com gestão de listas e conteúdo de e-mail", accedido el 18/04/2013 en www.myemma.com,

- E-mail Marketing, "Ferramenta para fazer marketing através do uso de e-mail com gestão de listas e conteúdo de e-mail", accedido el 18/04/2013 en www.mailchimp.com,

- E-mail Marketing, "Ferramenta para fazer marketing através do uso de e-mail com gestão de listas e conteúdo de e-mail", accedido el 18/04/2013 en www.shortburst.co.uk

- E-mail Marketing, "Ferramenta para fazer marketing através do uso de e-mail com gestão de listas e conteúdo de e-mail", accedido el 18/04/2013 en www.constantcontact.com (ferramentas de e-mail marketing)

- Google Feedburner, "Ferramenta para medir desempenho RSS", accedido el 01/04/2013 en www.feedburner.com

- Pagemodo, “O jeito mais fácil de personalizar e administrar uma página de fãs no Facebook, sem ter conhecimento técnico ou de design", accedido el 01/05/2013 en www.pagemodo.com 
- Peixe Urbano, "Compras coletivas para divulgação dos nossos produtos", adcedido el 05/05/2013 en http://www.peixeurbano.com.br/goiania/ofertas

- Groupon, "Compras coletivas para divulgação dos nossos produtos", accedido el 05/05/2013 en http://www.groupon.com.br/

- Saveme, "Compras coletivas para divulgação dos nossos produtos", accedido el 05/05/2013 en http://www.saveme.com.br/compra-coletiva/sao-paulo/

- Google Trends, "Ferramenta de SEO", accedido el 15/05/2013 en http://www.google.com.br/trends/

- Post Track the Buzz, "Monitoramento e análise de mídeas sociais", accedido el 15/06/2013 en http://www.postx.com.br/

- Linkedln, "Ferramenta para criar um rede de relacionamentos profissionais de nossa empresa, permitindo criar um meio de comunicação com nossos contatos", accedido el 15/06/2013 en http://br.linkedin.com/

- MundoPM, "Revista de nincho de gerenciamento de projetos", accedido el 28/06/2013 en http://www.mundopm.com.br/default.jsp

- Agendor Controle Comercial, "Software CRM online para gestão de clientes", accedido el 28/06/2013 en http://www.agendor.com.br/

- Wireframepro, "Ferramenta para construção de Wireframe de um site", accedido el 23/06/2013 en http://app.mockflow.com/

- Pencil Project, "Ferramenta para fazer desenho de telas e fluxos", accedido el 27/06/2013 en http://pencil.evolus.vn/

- Edgerank, "Ferramenta para aumentar a exposição e aumentar de fãs da empresa no Facebook", accedido el 01/07/2013 en http://edgerankchecker.com/

- Twtqpon, "Ferramenta para aumentar as vendas através de cupons do Twitter", accedido el 01/07/2013 en http://twtqpon.com/

- Tutvite, "Ferramenta para gerenciar eventos e grupos em media social", accedido el 01/07/2013 en http://twtvite.com

- Youtube activity, "Configuração para ajustar o youtube e conectá-lo por exemplo ao Facebook", accedido el 01/0/7/2013 en http://www.youtube.com/account\#sharing/activity

- Google Adwords, "Ferramenta para publicidade", accedido el 07/07/2013 en http://www.google.com.br/ads/adwords/?sourceid=awo\&subid=br-pt-ha-awbkhp0 26917975975 
- Audacity, "Sotware opensource para edição de som", accedido en 07/07/2013 en http://audacity.sourceforge.net/

- Calcular pagerank, "Ferramenta de google SEO", accedido el 15/07/2013 en http://calcularpagerank.com.br/

- Pagerank, "Calculadora de pagerank", accedido el 15/07/2013 en http://www.marketingdebusca.com.br/pagerank/

- Google Web Optimizer, "Software da Google usado para otimizar o nosso site", accedido el 18/07/2013 en http://services.google.com/websiteoptimizer/

- Facebook Painel Administrativo, "Ferramenta para gerenciar nossa página no Facebook", accedido en 19/07/2013 en www.facebook.com/pages/manage

- Zoomr, "Ferramenta para gestão de mídias sociais baseadas em imagens e vídeos", accedido el 21/07/2013 en www.zoomr.com

- Media Convert, "Ferramenta para gestão e conversão de mídias sociais baseadas em vídeos", accedido el 21/07/2013 en www.media-convert.com

- Photobucket, "Ferramenta para gestão e conversão de mídias sociais baseadas em vídeos ", accedido el 21/07/2013 en www.photobucket.com,

- Vuvox, "Media Creation", accedido el 21/07/2013 en www.vuvox.com

- Soundation, "Media para manipulação de sons e músicas" accedido el 21/07/2013 en http://soundation.com/studio

- Nielsen, Jakob. (2006) Estudo Publicado, accedido el 21/07/2013 en http://www.nngroup.com/articles/participation-inequality/

- McGee, Matt (Aug 16, 2013). "EdgeRank Is Dead: Facebook's News Feed Algorithm Now Has Close To 100K Weight Factors", accedido el 21/07/2013 en http://marketingland.com/edgerank-is-dead-facebooks-news-feed-algorithm-now-hasclose-to-100k-weight-factors-55908

- Slides.com: Creación, presentación e intercambio de slideshow, accedido el 21/08/2013 en www.slides.com

- Movie Maker: manejo de vídeos, accedido el 21/08/2013 en http://windows.microsoft.com/pt-br/windows-live/movie-maker

- Soundation: manejo de audio, accedido el 21/08/013 en www.soundation.com/studio

- Resultados Digitais: artículo sobre edgerank accedido el 21/07/2013 en http://resultadosdigitais.com.br/blog/como-o-edgerank-do-facebook-funciona-e-porque-isso-e-importante-para-sua-empresal 
- Software para comprobar cuantos retweets tuvimos, accedido el 20/06/2013 en www.checkretweet.com

- Software para la muestra del histórico de seguidores, accedido el 20/06/2013 en twittercounter.com

- Software para preparación de estatísticas del número de tweets, accedido el 20/06/2013 en tweetstats.com

- Revista Mundo PM, accedido el 28/06/2013 en www.mundopm.com.br

- Revista Pequenas Empresas Grandes Negócios, accedido el 28/06/2013 en http://q1.globo.com/economia/pme/index.html

- Software de CRM, accedido el 14/04/2013 en http://www.sugarforge.org/content/open-source/

- Software de CRM, accedido el 14/04/2014 en http://www.insightly.com

- Software para una programación de los perfiles profesionales, accedido el 14/04/014 en https://highrisehq.com

- Software para descubrir gente, accedido el 14/04/2014 en www.wefollow.com

- Software para permiso de uso de la misma en el sitio web especifico, accedido el 18/04/2014 em www.musicalley.com

- Software para linkar las actividades de Youtube, Facebook y Twitter, accedido el 30/06/2013 en http://www.youtube.com/account\#sharing/activity

- Software para para incluir nuestro canal al añadidor de vídeo y después importar el feed para Facebook usando el aplicativo Facebook Friendfeed ${ }^{37}$ o usando el propio feed creado para el blog y sitio web, accedido el 14/04/2014 en www.friedfeed.com

- Página Facebook de ABC Consultoria en https://www.facebook.com/ABCConsultoriaemProjetos accedido el 15/04/2014

- Software para analise de Twitter, accedido el 15/05/2014 en http://www.twitalyzer.com

- Software para creación del Ranking in Twitter, accedido el 15/05/2014 en https://twitter.com/rank1official

- Software para medir el posicionamiento en el ranking general de Twitter, accedido el 15/05/2014 en https://marketing.grader.com/ 


\section{NOTA ACLARATORIA}

Declaro bajo juramento que esta tesis fue elaborada por mí, que no utilicé ningún otro material que no haya dado a conocer en las referencias y que no utilicé frases o párrafo de otros autores, que este trabajo de tesis nunca ha sido presentado ante un comité de evaluación de tesis y que no transgreda derechos de terceros.

Ângelo José Albino Braga 